\title{
Heat resilience of apartment buildings in Korea and Germany: comparison of building design and climate
}

\author{
Christoph Schünemann ${ }^{1}$ (I) $\cdot$ Seoyeon Son ${ }^{1} \cdot$ Regine Ortlepp ${ }^{1}$
}

Received: 1 December 2021 / Accepted: 17 January 2022 / Published online: 6 February 2022

(c) The Author(s) 2022

\begin{abstract}
A major concern in climate adaptation is to enhance the heat resilient design of residential buildings. However, recent scientific literature addressing overheating analysis is only focussing on individual countries. In this article, we discuss how different design of representative apartment buildings in two countries influences the overheating risk or cooling demand and what conclusions can be drawn from it. This is done for a low-rise apartment building located in Germany and a highrise building in South Korea applying building performance simulation. Both countries are located in the moderate climate zone, but regional differences in frequency of tropical nights and radiant summer days lead to significant differences in overheating intensity ( $800 \mathrm{Kh} / \mathrm{a}$ for the German and $5100 \mathrm{Kh} / \mathrm{a}$ for the Korean) or cooling demand (1800 kWh for the German to $1300 \mathrm{kWh}$ for the Korean). The lower cooling demand but much higher overheating intensity of the Korean building compared to the German is mainly caused by the different solar heat gain due to the glazed balcony design of the Korean building where these balcony rooms are not actively cooled. On the contrary, the common internal façade insulation of Korean buildings results in a higher overheating risk compared to the German building and in addition the lower potential of passive cooling by natural ventilation due to the necessity of insect screens in Korea. The large effect of implementing heat adaptation measures on overheating risk reduction or cooling demand (up to 90\%) clearly demonstrates that both buildings are far away from a heat resilient design and that heat adaptation measures can address both climate change adaptation and mitigation.
\end{abstract}

Keywords Heat resilience · Overheating · Cooling demand · Apartment buildings · Climate · Building performance simulation

\section{Introduction}

The ongoing global warming trend leads to warmer summers with and an increase in severity and frequency in heat wave events [1]. Accordingly, the relevance of heat resilient cities, districts and buildings is increasing and is expected to rise in future. Especially for large cities, additionally burdened by strong urban heat island effects in summer [2,3], this dangerous trend can lead to discomfort, restricted concentration abilities, increase in health risk up to heat mortality [4, 5]. For residential buildings located in moderate climates, the warming trend and projection is expected to induce two changes. Either the effectiveness of passive cooling of buildings by natural ventilation will be reduced or buildings need

Christoph Schünemann

c.schuenemann@ioer.de

1 Leibniz Institute of Ecological Urban and Regional Development, Weberplatz 1, 01217 Dresden, Germany to be actively conditioned by cooling devices leading to an increase in cooling energy demand.

In the present case study, the heat resilience of two apartment buildings located in different countries but in the same moderate climate zone but with different local climate conditions is analysed. The high-rise building (HRB) is originated in the large city of Seoul, South Korea, whereas the low-rise building (LRB) is located in the city of Berlin, Germany. Although both buildings are located in the moderate climate zone, the summertime conditions reveal significant differences affecting overheating intensity in buildings or differences in cooling demand. For both buildings, a 3D model was created including detailed building physics and is used for building performance simulation (BPS). This method enables the opportunity to virtually place both buildings in the modelling in the same city to separately evaluate the effect of different climate conditions and of different building design on overheating or cooling demand. In addition, the different effectiveness of several heat adaptation 
measures can be analysed for both different climate and different building design. In this way, the influence of each parameter in the model can be analysed independently. The implementation of wind- and temperature gradient-driven air exchange by natural ventilation is implemented in the applied BPS tool and enables that the significant influence of passive cooling by natural ventilation can be displayed in a realistic manner.

The comparison of heat resilience for two buildings in two different countries-performed in this study—is motivated by the fact that the authors did not found any scientific literature comparing the heat resilience of apartment buildings in different countries. In the past, the scientific literature concerning overheating analysis in residential buildings was dominated by numerous investigations located in Great Britain [6-24]. However, in the last years a significant increase in studies focussing overheating evaluations could be obtained all around the globe, e.g. for China [25], in Sudanese [26], for Canada [27], for Honduras [28], for South Korea [29, 30], for Austria [31, 32], for Italy [33], for Sweden [34] or for Germany [35, 36]. This trend highlights that overheating in residential buildings becomes an important global research topic, albeit the terminology of overheating is related to different comfort standards and climate conditions for different countries, cultures and climates. Most of the recent studies focus on overheating analysis using the method of BPS for apartment building types located in cities. Despite the rising number of scientific studies, all discussed research articles solely focus on overheating of buildings within one country.

In this study, we investigate the heat resilience (overheating intensity) and energy efficiency (cooling demand) of two representative apartment buildings from two different countries to address the three objectives: first, to demonstrate how strong differences in regional building design of apartment building types in the two country influences the overheating risk and cooling demand; second, to analyse how significant small variations in local climate conditions affect the overheating intensity and cooling demand, although both countries are located in the same moderate climate zone; and third, by implementing different heat adaptation measures we compare the effectiveness on overheating or cooling demand reduction in dependence of the building type and climate and discuss the individual most suitable adaptation measures. Focussing on these three research questions, we contribute to the scientific discussion in the field of developing suitable building designs for heat resilient and energyefficient apartment buildings, dependent on the local climate conditions.

\section{Methods}

\section{Climate conditions and meteorological data}

Both countries Germany and South Korea are located in the moderate climate zone. Both exhibit a climate with four seasons. For South Korea, an annual cycle with wet conditions in summer time and dry conditions in winter time is typical. As a result, the time between June and August is characterised by a rainy period leading to high ongoing high air humidity and high air temperatures (see Fig. 1a and b). In comparison in Germany, a larger amount of clear, sunny summer days are common caused by frequent changes of maritime and continental conditions. The direct solar irradiation development of Germany and South Korea in Fig. 1c highlight this differences (especially for the period from June 1 to August 31), although Germany is located $15^{\circ}$ more northern.

The more frequent occurrence of cloudy conditions in South Korea leads to another impact on outdoor air temperature. While in German summer the minimum air temperatures at night are typically below $20^{\circ} \mathrm{C}$, the cloudy conditions in South Korea lead to reduced nocturnal heat emission and thus to minimum air temperatures often above $20{ }^{\circ} \mathrm{C}$ (tropical nights). This difference is highlighted in Table 1 by opposing the number of tropical nights of 3 for the meteorological data of Berlin (Germany) and 58 for Seoul (South Korea) during the whole summer. Accordingly, the mild nights in South Korea lead to a worse efficacy of passive cooling of buildings by window ventilation compared to the colder nights in Germany.

While the maximum daily outdoor air temperatures and the number of hot days (maximum air temperature during a day larger than $30^{\circ} \mathrm{C}$ ) are similar for both countries (see Table 1), the intraday air temperature differences are much higher in Berlin compared to Seoul (Fig. 1a) which is caused by the significantly milder nights in South Korea. This results in an average outdoor temperature of $20.0^{\circ} \mathrm{C}$ in Seoul and only $16.0^{\circ} \mathrm{C}$ in Berlin for the period from June 1 to August 31 (see Table 1). For passive cooling of buildings by natural ventilation, the wind conditions are important as well. Figure 1a and Table 1 demonstrate that the wind speed in both countries is comparable but with more windy periods in Germany due to more frequent changes between maritime and continental conditions. However, for hot days calm weather is characteristic for both countries and observed for Berlin and Seoul.

For the BPS, at least hourly time resolved values for the meteorological parameters outdoor air temperature, wind speed, wind direction, direct solar irradiation and diffuse solar irradiation are required. Therefore, the meteorological data of Potsdam "Test-Reference-Year 2010-04 warm 
a Outside air temperature in $2 \mathrm{~m}$ height $\left({ }^{\circ} \mathrm{C}\right)$

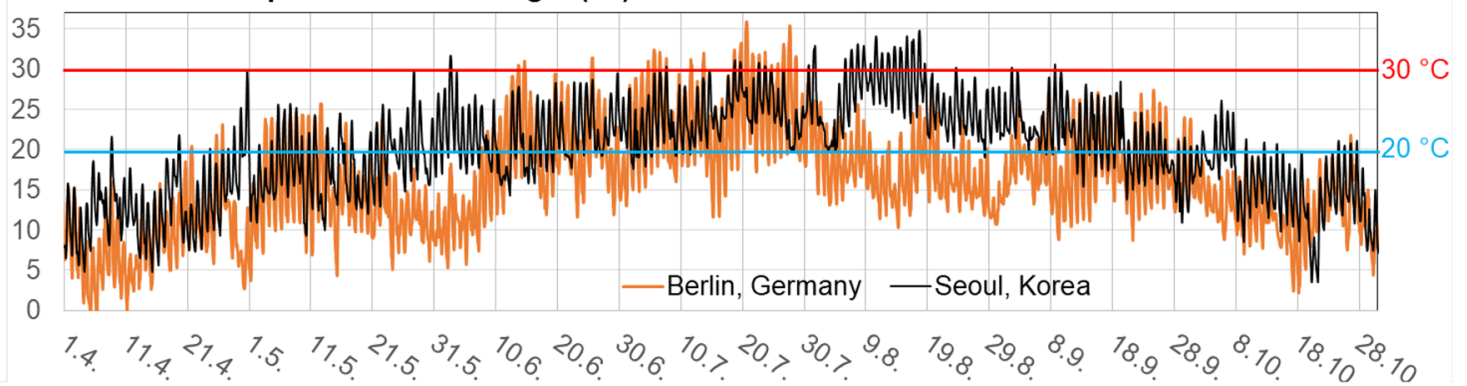

b Relative air humidity (\%)

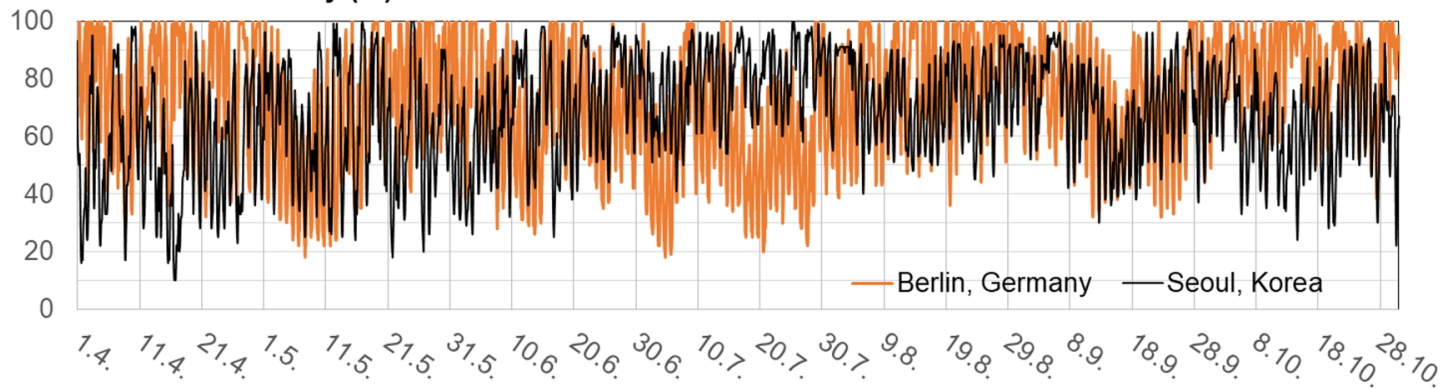

c Direct solar irradiation on horizontal $\left(\mathrm{W} / \mathrm{m}^{2}\right)$

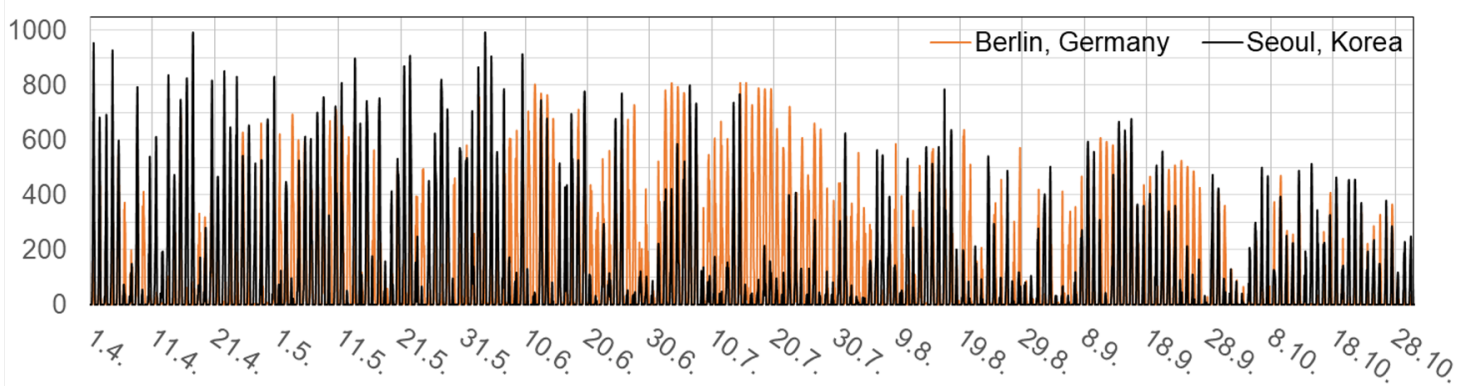

d Diffuse solar irradiation on horizontal $\left(\mathrm{W} / \mathrm{m}^{2}\right)$

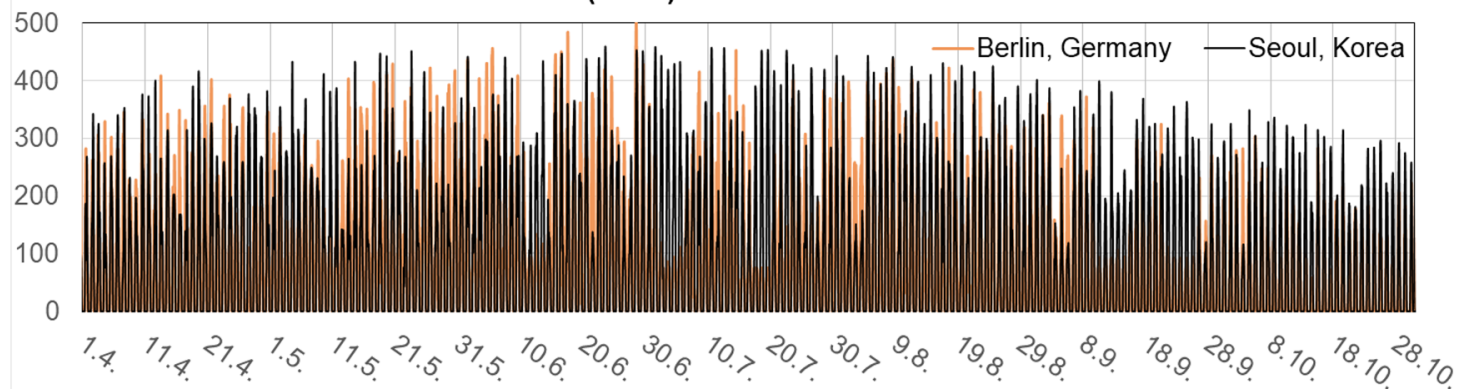

e Wind speed in $10 \mathrm{~m}$ height $(\mathrm{m} / \mathrm{s})$

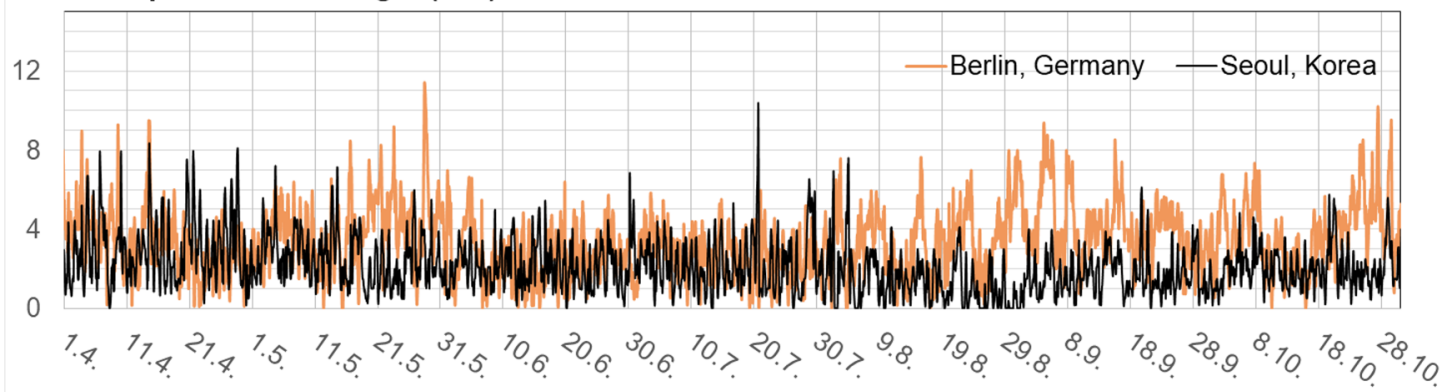

Fig. 1 a Outdoor air temperature ( $2 \mathrm{~m}$ height above ground), b relative air humidity, c direct solar irradiation, d diffuse solar irradiation and $\mathbf{e}$ wind speed time series (10 $\mathrm{m}$ height above ground) of the selected meteorological data chosen for BPS for Berlin, Germany, and Seoul, Korea, from April 1th to October 31th 
Table 1 Characteristics of meteorological data chosen for BPS for Berlin, Germany (location of LRB), and Seoul, Korea (location of HRB) for the period from April 1 to October 31 // June 1 to August 31, corresponding to Fig. 1

\begin{tabular}{lll}
\hline Parameter & Berlin, Germany (LRB building) & Seoul, Korea (HRB building) \\
\hline Average outdoor air temperature & $16.0^{\circ} \mathrm{C} / / \mathbf{1 9 . 5}{ }^{\circ} \mathbf{C}$ & $20.0^{\circ} \mathrm{C} / / \mathbf{2 4 . 1}{ }^{\circ} \mathbf{C}$ \\
Maximum outdoor air temperature & $35.9^{\circ} \mathrm{C} / / 35.9^{\circ} \mathrm{C}$ & $34.7^{\circ} \mathrm{C} / / 34.7^{\circ} \mathrm{C}$ \\
Number of hot days $\left(>30^{\circ} \mathrm{C}\right)$ & $20 / / 20$ & $24 / / 22$ \\
Number of tropical nights $\left(>20^{\circ} \mathrm{C}\right)$ & $3 / / \mathbf{3}$ & $58 / / \mathbf{5 2}$ \\
Average wind speed $(10 \mathrm{~m}$ height) & $3.4 \mathrm{~m} / \mathrm{s} / / 2.9 \mathrm{~m} / \mathrm{s}$ & $2.1 \mathrm{~m} / \mathrm{s} / / 1.9 \mathrm{~m} / \mathrm{s}$ \\
Maximum wind speed $(10 \mathrm{~m}$ height) & $11.4 \mathrm{~m} / \mathrm{s} / / 8.0 \mathrm{~m} / \mathrm{s}$ & $10.4 \mathrm{~m} / \mathrm{s} / / 10.4 \mathrm{~m} / \mathrm{s}$ \\
Global solar irradiation sum (horiz.) & $947 \mathrm{kWh} / / 515 \mathrm{kWh}$ & $964 \mathrm{kWh} / / 410 \mathrm{kWh}$ \\
Direct solar irradiation sum (horiz.) & $507 \mathrm{kWh} / / \mathbf{2 9 2} \mathbf{~ k W h}$ & $450 \mathrm{kWh} / / \mathbf{1 6 0} \mathbf{~ k W h}$ \\
Diffuse solar irradiation sum (horiz.) & $440 \mathrm{kWh} / / 223 \mathrm{kWh}$ & $514 \mathrm{kWh} / / 250 \mathrm{kWh}$ \\
\hline
\end{tabular}

The most relevant differences are highlighted in bold font [37, 38]

\begin{tabular}{lll}
\hline & Germany // Berlin & South Korea // Seoul \\
\hline Land area & $357,022 \mathrm{~km}^{2}$ & $100,363 \mathrm{~km}^{2}$ \\
population & $83.2 / / 3.7$ & $51.7 / / 10.1$ \\
Average living area per person & $47.0 \mathrm{~m}^{2} / / 39.3 \mathrm{~m}^{2}$ & $28.5 \mathrm{~m}^{2} / / 25.8 \mathrm{~m}^{2}$ \\
Average living area per household & $93 \mathrm{~m}^{2} / /-$ & $70.0 \mathrm{~m}^{2} / /-$ \\
Share of flats located in apartment buildings* & $52 \% / /-$ & $51 \% / /-$ \\
\hline
\end{tabular}

*more than 3 flats in one building [41-46]
Table 2 Comparison of specifics of both countries, South Korea and Germany, and (separated with "//") the corresponding capitals Seoul and Berlin, respectively centre of Seoul and erected in the year 1999, was chosen. For Germany, a 6-storey LRB, located in the centre of Berlin and erected in the time span of 1960 to 1990, was selected. The LRB was renovated in the recent years including improved insulation and installation of an elevator. Figure 2 shows views and floor plans of both buildings. For the HRB, every floor consists of two flats, located on the opposite of the staircase (in sum 40 flats, each with $80 \mathrm{~m}^{2}$ living area), while for the LRB every floor consists of three flats (in sum 18 flats, with individual living areas between 55 and $65 \mathrm{~m}^{2}$ ). The HRB type in South Korea is mainly inhabited by residents of the societal middle class, while the LRB type in Germany is commonly used for social housing.

\section{Building design and building physics}

To compare the building properties and building physics, a detailed research of the German and South Korean apartment building stock was performed at the beginning of this study including local experiences. As a result, several regional differences and similarities in building physics could be achieved between both countries, originated by different cultural and social background as well as climate conditions. Caused by the high diversity of apartment building types within the country, our findings describe average differences in the building stock for both countries in a generalised form, which of course can vary significantly for individual apartment buildings. For German and Korean 
a Low-rise building (LRB): Side view

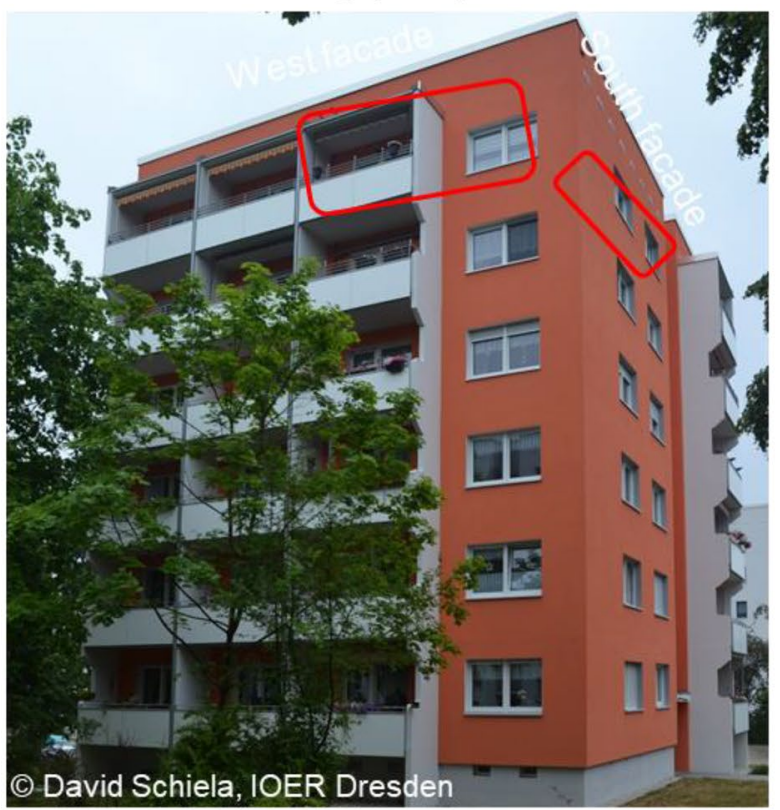

c Low-rise building (LRB): floor plan

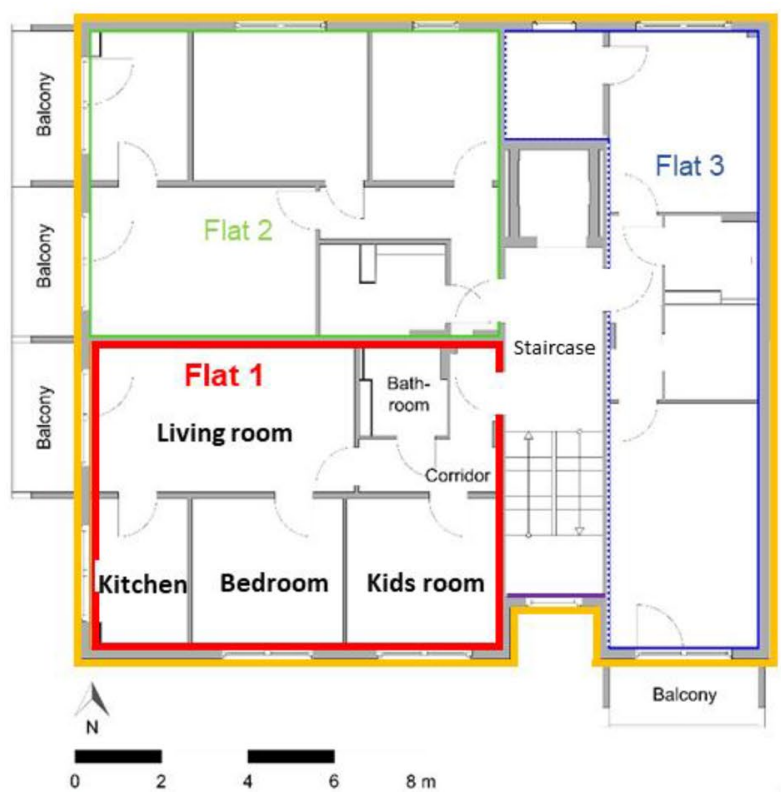

b High-rise building (HRB): Side view
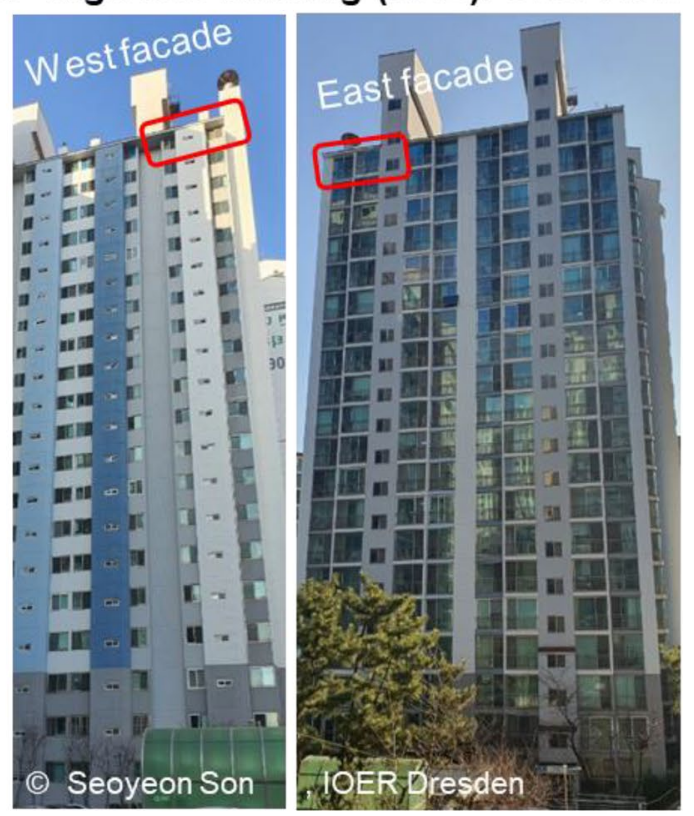

d High-rise building (HRB): floor plan

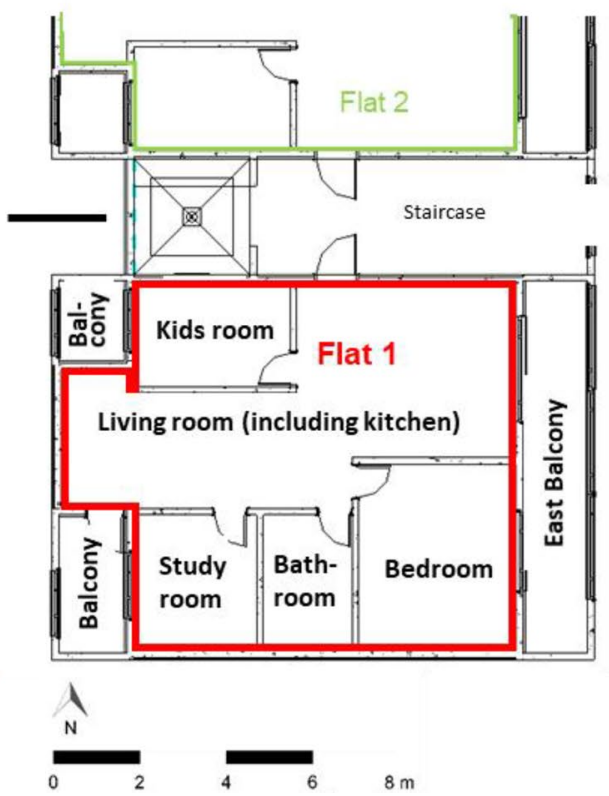

Fig. 2 Views and floor plans of the selected a \& c Low-rise building (LRB), located in Berlin (Germany) and $\mathbf{b} \& \mathbf{d}$ high-rise building (HRB), located in Seoul, South Korea. The red border mark the position of the investigated flat at the top floor. The orange border mark the external envelope insulation of the building for the LRB while for the HRB the flats are insulated internally, marked by the red and green borders of the flat (balconies are positioned outside the building envelope) apartment buildings, the following general similarities are obtained:

1. Construction The constructional part (walls and ceilings) of the apartment buildings with more than three storeys is typically made of concrete in both countries and can be also the found in the selected HRB and LRB buildings.

2. Active cooling Apartment buildings in South Korea older than 20 years are commonly not equipped with permanently installed technical cooling devices and only with technical heating. These buildings can only be passively 
cooled by window ventilation, as it is the case for the chosen HRB and LRB building. However, because of climatological differences it is common that inhabitants install cooling devices in their flat, especially in the living room and sometimes in the bedroom [47]. In Germany, technical cooling in apartment buildings is uncommon. Hence, desired wall penetrations for exhaust air pipes of cooling devices are hard to realise in Germany, especially for tenants. In contrast, in South Korea such penetrations are standard in buildings. Newer apartment buildings in South Korea are often equipped with technical cooling, which is not common for German new buildings.

3. Ventilation system Existing middle-class apartment buildings typically also do reveal technical ventilation system in both countries to guarantee fresh air supply or to heat and cool the flat. Even for new buildings, the implementation of such ventilation systems is not mandatory or standard in Germany or South Korea and remains an additional option. The selected HRB and LRB building do only exhibit an exhaust air ventilation for the bathroom but no ventilation system with fresh air supply.

4. Shading system For both countries, installation of external sun shading system is uncommon. The chosen LRB and HRB building do not have any shading systems. In Germany, this is can only be found for newer buildings with large windows with east, south or west orientation.

Besides these obtained similarities, significant differences are found in the building physics between Germany and South Korea, leading to different overheating risk, cooling demand and heating demand:

1. Wall insulation While the sandwich panel elements of the exterior wall of the LRB (Germany) are insulated by a $10-\mathrm{cm}$-thick mineral wool layer as external insulation, the HRB (South Korea) is insulated by a 5-cm-thick extruded polystyrene foam (XPS) layer as internal insulation layer. The two types of construction are common practice in Germany and South Korea, respectively. While in Germany external insulation of facades is standard and internal insulation is seen very critical due to thermal bridges and risk of condensation, our research on South Korean buildings highlights that internal insulation is standard. However, resident interviews do not reveal significant condensation issues or mould on exterior walls. This is even more remarkable by the fact that our research for South Korean revealed that thick internal insulation layers by XPS of $14 \mathrm{~cm}$ are common for new buildings to enhance energy efficiency. Internal insulation with high thicknesses are found to be common in China as well [25]. South Korean stand- ards clearly describes how internal insulation needs to be applied [48] although condensation problematics are obtained for some balcony walls [49]. Nevertheless, the reduced heat storage capacity of rooms by internal insulation reduces the potential to buffer high solar or internal loads and thus rises the risk of high room temperatures and uncomfortable indoor conditions. In this study, we investigated in detail the impact of this difference in insulation type between Germany and South Korea.

2. Balconies In both countries, the balconies are commonly located outside of the thermal building envelope, but in South Korea balconies are usually fully closed by windows of sun protection glazing, while balcony of German apartments are mostly open without any glazing. This difference is also present for the selected HRB (South Korea) and LRB (Germany). Thus, while the HRB balconies significantly rise in room temperature with ongoing solar irradiation, the LRB balconies, connected to the outdoor air, do not. This difference is also common for most buildings in Germany and South Korea and is correlated to the different use of the balcony [50].

3. Window glazing While in Germany triple glazing including an insulation coating are commonly installed in new buildings, windows in South Korea consist of double glazing including a sun protection layer. Thus, while in Germany windows are optimised for low heat energy loss during winter time, South Korean buildings focus on reducing the solar heat gain during summer time [51]. For the selected HRB and LRB building, this is depicted representatively as shown in Table 3.

4. Window opening The windows in South Korean buildings can be opened by sliding the windows sideways. In contrast, window wings in Germany can be commonly tilted (to guarantee small opening degrees) and turned at a vertical axis to fully open them.

5. Insect screen The higher air humidity in South Korea leads to a higher exposure of insects. Accordingly, nearly all windows in South Korea are equipped with insect screens as standard. Whereas in Germany insect screens are not common, especially for multi-residential buildings. This difference is crucial because the insect screen nearly halves the air exchange rate to the outside when windows are opened [52], leading to a reduced passive cooling efficacy for Korean building by cool outdoor air. The effect of this difference is demonstrated for the selected HRB and LRB later on.

Detailed structural component information of the selected HRB and LRB can be found in Table 3. 


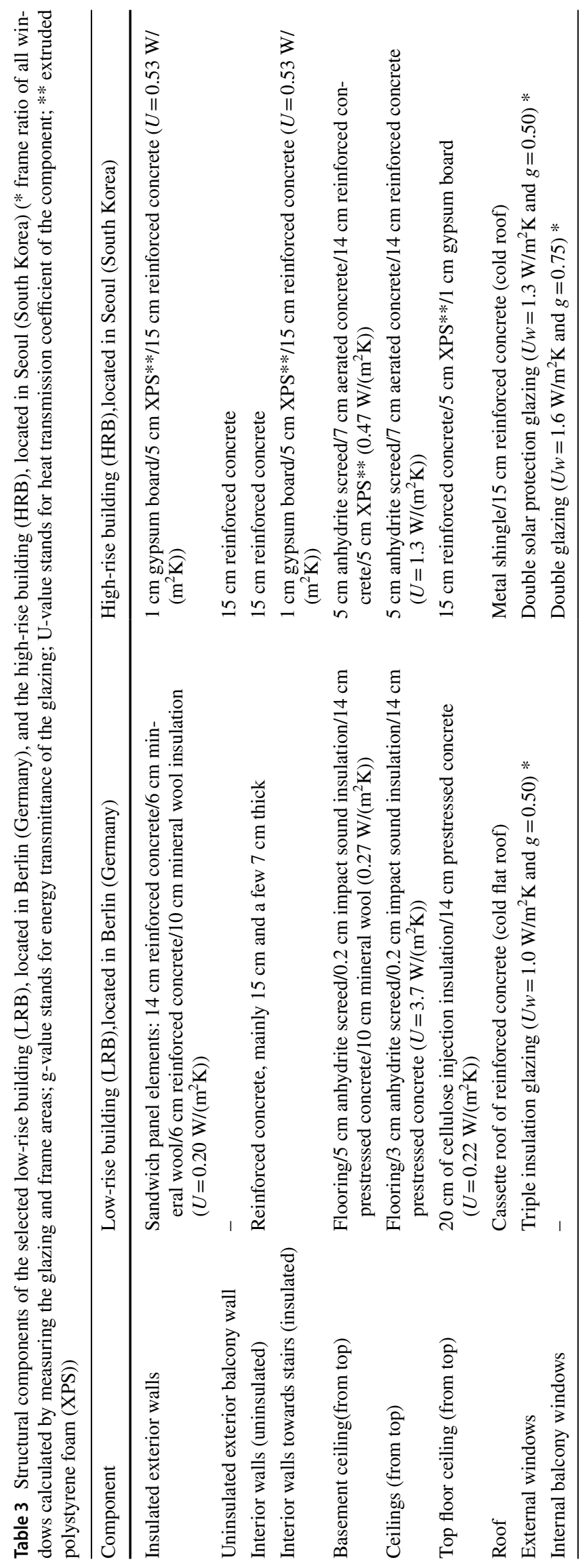




\section{Building performance simulation and parametrisation}

To simulate the evolving room temperatures for both HRB and LRB, all flats of both apartment buildings were simulated using the BPS software IDA ICE $4.8^{1}$ [53]. Building components and material layers were implemented as listed in Table 3 to ensure the desired realistic heat storage and transmission dynamics for each room. Details about the parametrisation and air exchange of the BPS models can be found in the appendix.

The passive cooling of rooms by natural ventilation is a crucial element and has a large impact on overheating evaluation. Therefore, we developed several daily window ventilation profiles (WVP) from residents' questionnaires in an earlier study and analysed their impact on overheating [54]. For air exchange calculations, the duration and degree of window opening is essential to be integrated in the BPS model. The opening duration is taken from the time tables "Noise" (visualisation see Table 8, Appendix) developed earlier [54]. In this WVP the windows of the flats are opened in the morning and evening (from 6 to 8 am and from 6 to $10 \mathrm{pm}$ ) if outdoor air temperature is lower than room temperature and room temperature is above $24{ }^{\circ} \mathrm{C}$. The room doors and internal windows are opened in the morning and evening (from 6 to 8 am and from 6 to $10 \mathrm{pm}$ ) to guarantee cross-ventilation. This WVP describes a good practice of using the cooling potential of natural ventilation under the limitation that the windows remain closed during bedtime because of outdoor noise, risk of precipitation, risk of burglary, etc.

The window opening area in the BPS model is estimated by measurement of the real opening cross section of the individual windows and leads to:

- Window opening degree for the HRB including the 50\% reduction (reduction estimated according to Kittas et al. (2008) in air exchange by the installed insect screen: $20 \%$ of the window area for the window of the east balcony and $25 \%$ for the three west-oriented windows (see Fig. 2)

- Window opening degree for the LRB (without insect screen): $70 \%$ of the window area for the window door of the west balcony (small window next to remain closed) and $35 \%$ for the double-wing windows in kitchen, bedroom and kids room (see Fig. 2), assuming that only one wing is opened.

\footnotetext{
1 Validation history of IDA ICE: http://www.equaonline.com/iceuser/ new_validationreports.html and http://www.equaonline.com/iceuser/ new_certificates.html (accessed at 26.02.2021).
}

For the simulation scenarios where active cooling is applied, the windows remain closed all the time (neglecting the short times of window opening for fresh air in reality) while all room doors (except bathroom) remain open.

\section{Overheating criteria}

The solely analysis of the evolving room temperatures from the BPS model is only partially expressive for drawing conclusions on heat resilience and overheating intensity. In the literature, different indicators exist to evaluate overheating [55-59]. Because no unique criteria of overheating assessment is available [11], we decided to use the indicator developed in DIN 4108-2 of the so-called overtemperature degree hours (TDH). This indicator gives not only information for how many hours per year a temperature limit is exceeded but also by which degree, i.e. whether only by $1 \mathrm{~K}$ or even by $5 \mathrm{~K}$ within one hour. More precisely, the TDH indicator describes the cumulative product of exceedance time and exceedance magnitude of the temperature over one year, given in Kh/a. The critical threshold of TDH is defined to be $1200 \mathrm{Kh} / \mathrm{a}$ according to DIN 4108-2. This means that if the THD in a building is higher than this limit value, then the building is not heat resilient and adaptation measures are required. Because we do not differ in room use in our BPS model, we evaluate the overheating over the whole summer time, $24 \mathrm{~h}$ a day, for all rooms.

\section{Results}

\section{Impact of building design and climate conditions on heat resilience}

For comparison of heat resilience of the HRB and the LRB, detailed BPS of both buildings (including all flats) were performed at its original location (HRB in Seoul, South Korea; LRB in Berlin, Germany) using the corresponding meteorological data. For the reasons of clarity, the presentation of the BPS results will be only focussed on the living room for both buildings, centrally located in the flat. In Fig. 3, the different room temperature time series for the month of July and August are depicted, including derived overheating intensity by means of THD and maximum room temperature. Comparing the first and the top floor level in the building shows that the top floor dwelling show a higher overheating risk as known from the literature [24, 60]. This effect is more pronounced for the HRB in Seoul as for the LRB in Berlin reasoned in the lower insulation the top floor ceiling and the lower heat storage capacity of the HRB flat in comparison with the LRB. Comparing both buildings the overheating intensity in the HRB is significantly higher with a factor six in TDH (5100 Kh/a for HRB to $800 \mathrm{Kh} / \mathrm{a}$ for 


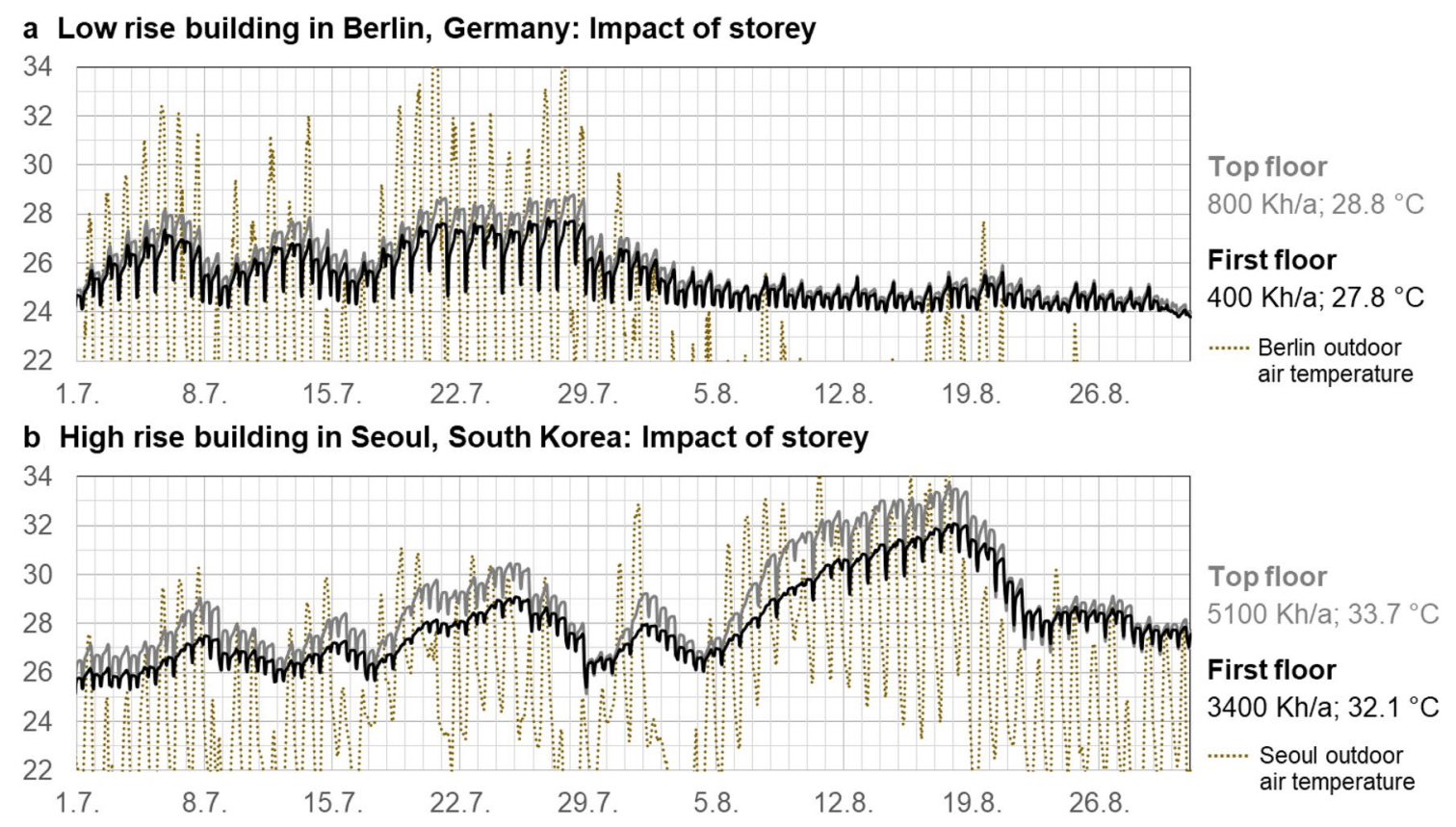

Fig. 3 Storey dependency of evolving room temperatures of the living room for the selected a Low-rise building (LRB) and b high-rise building (HRB) from July 1th until August 31 . Besides the diagrams the derived overheating intensity as TDH (in Kh/a) and maximum

LRB to floor) compared to the living room in the LRB. The reason for the strong deviation is mainly originated by the different climate conditions. As visible in Fig. 3, the indoor room temperature evolution is connected to the outdoor air temperature conditions. Analysing the daily room temperature variations, a strong drop can be obtained for the LRB in the morning hours. This is caused by the cool outdoor air in the early morning hours for the German climate, effectively cooling down the living room when the windows are opened (6 to $8 \mathrm{am}$ ). In comparison, this impact is much lower for the HRB, mainly caused by the milder nights and morning hours for the climate of Seoul.

To distinguish which differences in evolving room temperature can be ascribed to different building design and which to location and climate conditions, we virtually located both buildings in the same city. Thus, the HRB and LRB can be compared under the assumption to be both located in Seoul or Berlin with the corresponding climate conditions. In Fig. 4a, both buildings are assumed to be placed in Berlin, evincing that the heat resilience of the LRB is significantly lower than the HRB (TDH of 800 to $2200 \mathrm{Kh} / \mathrm{a}$, respectively). However, when comparing both buildings assumed to be located in Seoul, the difference in overheating decreases significantly (TDH of LRB of $4600 \mathrm{Kh} / \mathrm{a}$ compared to $5100 \mathrm{Kh} / \mathrm{a}$ for the HRB) while the overheating intensity for both buildings is much higher compared to the location of Berlin. The latter can be ascribed by room temperature are depicted. The window ventilation profile "Noise" was applied for both building (closed windows during night), the windows of the HRB are equipped with an insect screen reducing the air exchange

differences in outdoor air temperatures, especially during the night. The question remains why the difference in overheating intensity between the HRB and LRB is considerably larger for the location of Berlin in comparison with Seoul. The temperature drop in the morning hours after hot days in the living room of the LRB and HRB (when the windows are opened from 6 to $8 \mathrm{am}$ ) is comparable, demonstrating a comparable air exchange (see Fig. 4). This is reasonable because both flats exhibit a similar opened ventilation crosssectional areas of the windows of around $4 \mathrm{~m}^{2}$ in sum and similar opportunities of cross-ventilation (see Fig. 2).

To further clarify this difference, the insulation type of both buildings was varied. Instead of external insulation, the walls and top floor ceiling of the LRB were insulated with a 6-cm-thick internal XPS layer, similar to the HRB insulation (see Table 3). Analogous the internal insulation of the building envelop of the HRB was changed to an external insulation with the same heat transmission coefficient. The results in Fig. 5 clearly indicate that using external insulation leads to lower TDH and thus higher heat resilience for both buildings. The temperature during the day increases much faster if internal insulation is used, especially in the LRB (located in Germany). This clearly highlights the importance of heat storage capacity to reduce high daily room temperature maxima by solar or internal heat gains. Comparing the TDH and maximum room temperature in Figs. 4 and 5, the type of insulation is responsible for the major difference between 


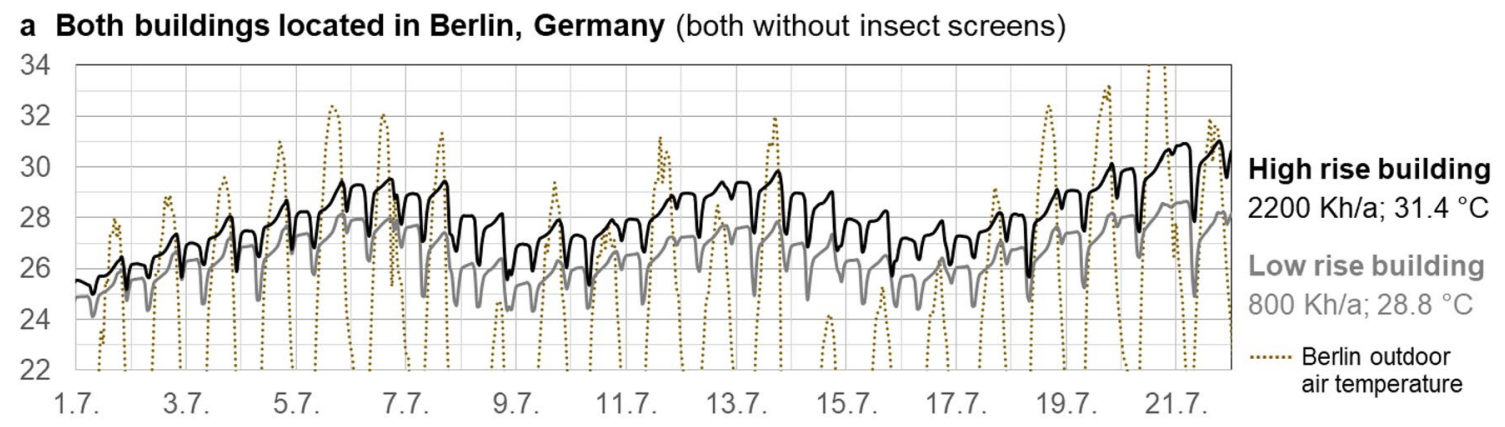

b Both buildings located in Seoul, South Korea (both with insect screens)

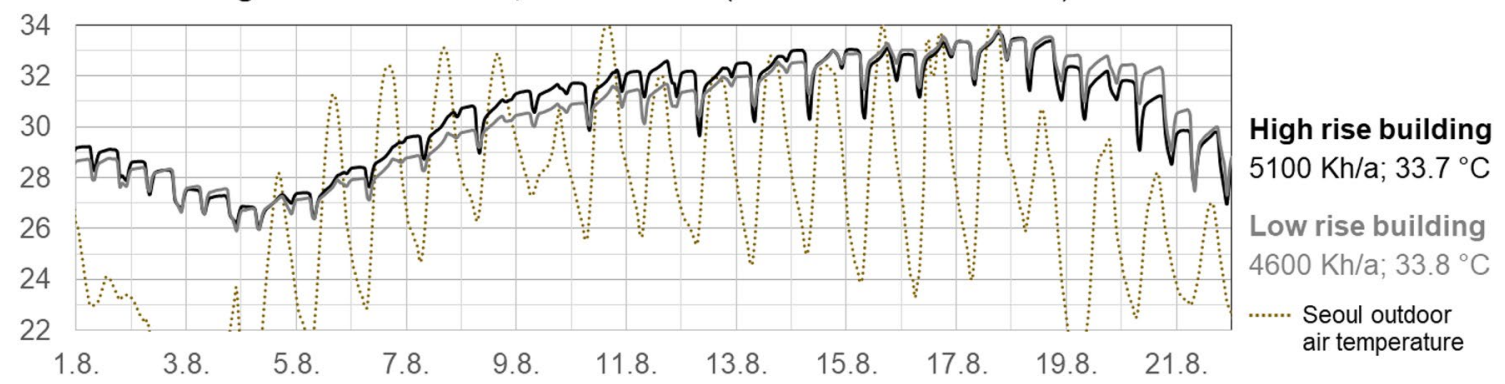

Fig. 4 Impact of location and climate: Evolving room temperatures of the living room (top floor) for the low-rise building (LRB) and the high-rise building (HRB) assuming that both are located in a Berlin (Germany) or b Seoul (South Korea). For both locations, the summer month with the highest outdoor air temperatures is depicted. Besides the diagrams the derived overheating intensity as TDH (in $\mathrm{Kh} / \mathrm{a}$ ) and maximum room temperature are visualised. For the location of Seoul, the windows of both buildings are equipped with an insect screen, whereas for Berlin no insect screens are applied for both
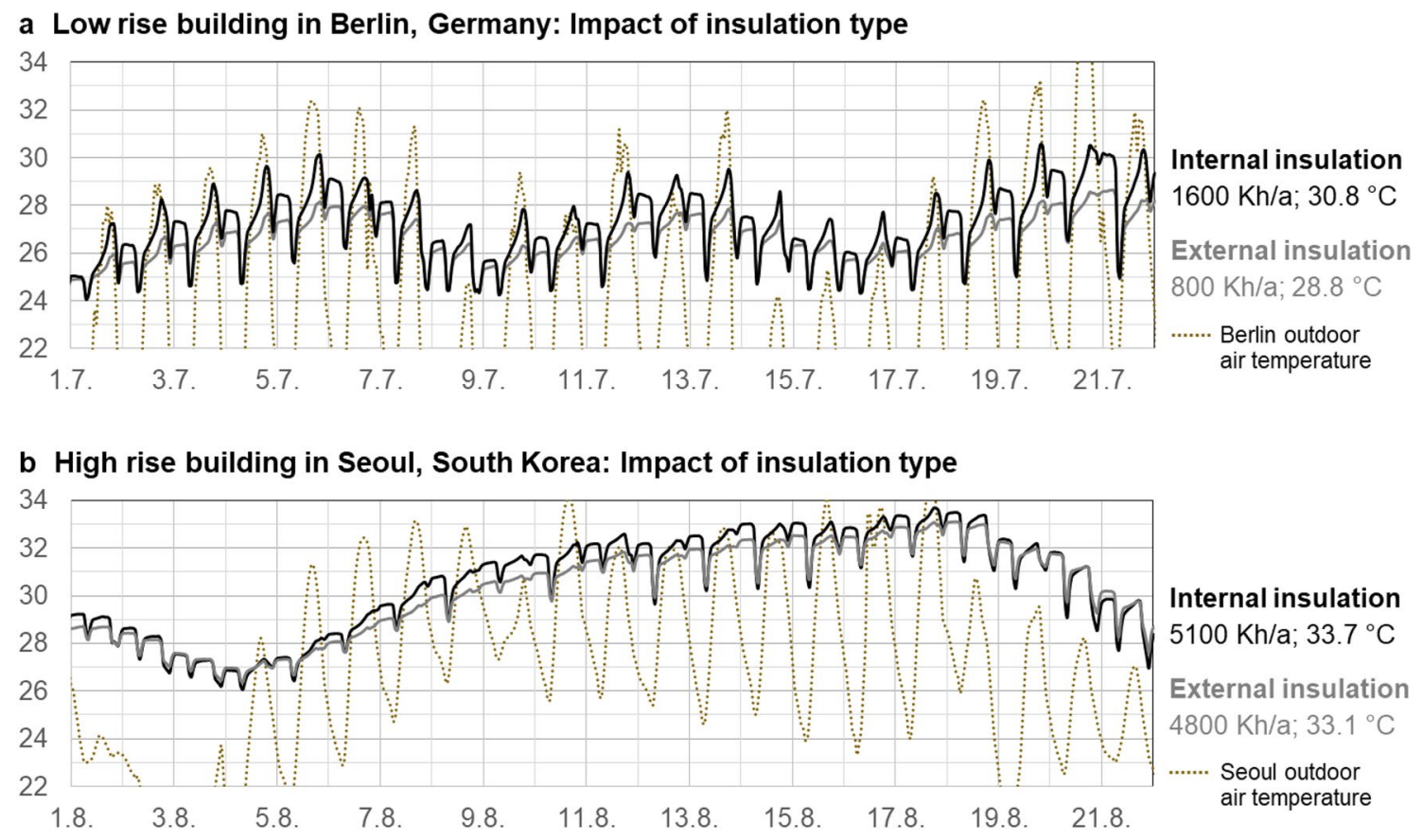

Fig. 5 Impact of insulation type: Evolving room temperatures of the living room (top floor) for the a low-rise building (LRB) in Berlin and b high-rise building (HRB) in Seoul comparing internal and external building envelop insulation. Besides the diagrams the derived overheating intensity as TDH (in $\mathrm{Kh} / \mathrm{a}$ ) and maximum room temperature are visualised. Windows of the HRB are equipped with an insect screen, whereas for the LRB no insect screens is applied 

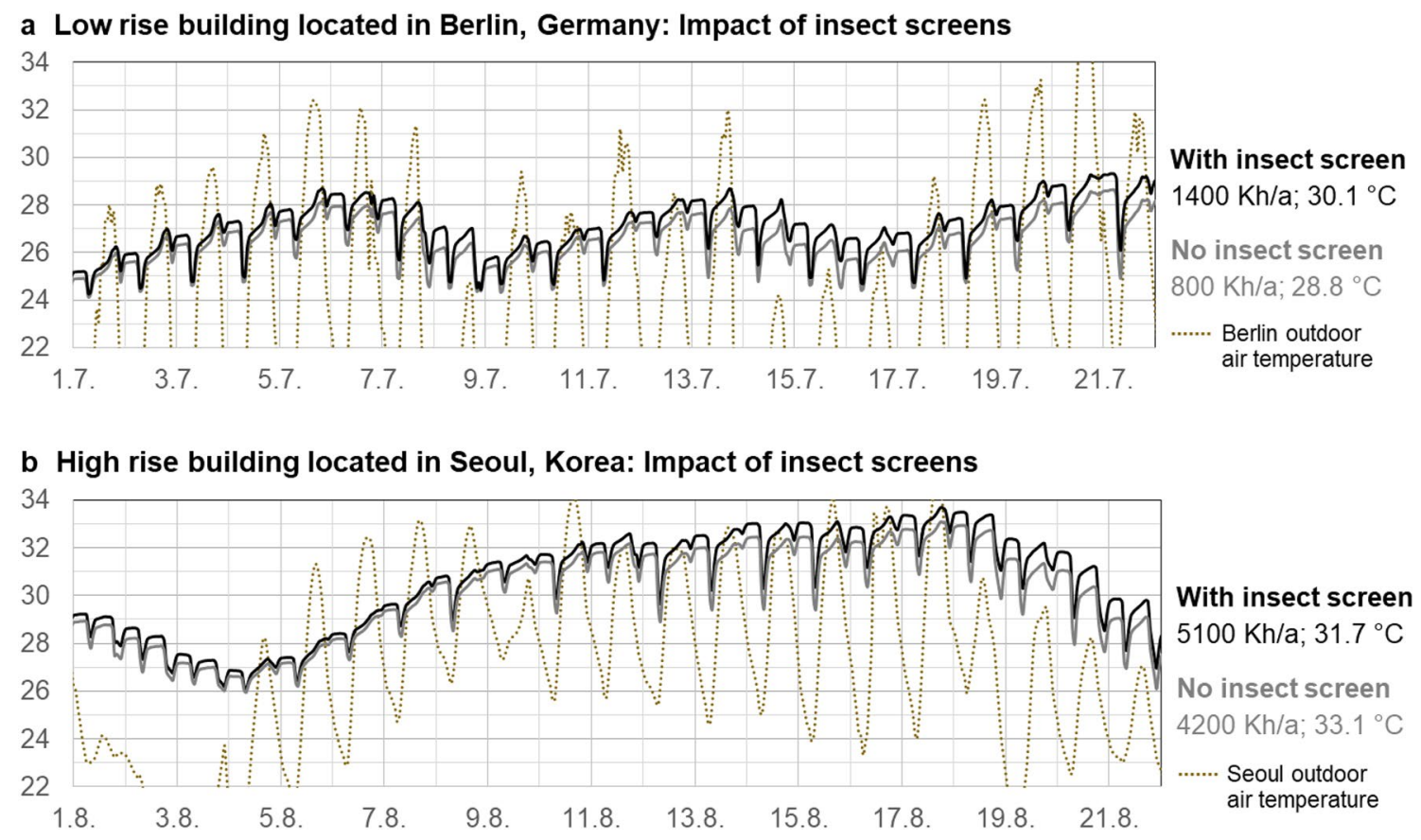

Fig. 6 Impact of insect screen on natural ventilation: Evolving room temperatures of the living room (top floor) for the a low-rise building (LRB) in Berlin and b high-rise building (HRB) in Seoul comparing

LRB and HRB overheating. Applying internal insulation, the TDH of the LRB in Berlin with a value of $1600 \mathrm{Kh} / \mathrm{a}$ are comparable to the HRB in Berlin with $2200 \mathrm{Kh} / \mathrm{a}$. Applying external insulation, the TDH of the HRB in Seoul with a value of $4800 \mathrm{Kh} / \mathrm{a}$ are similar to the LRB in Seoul with $4600 \mathrm{Kh} / \mathrm{a}$.

Another major difference between Korean and German buildings is that insect screens on windows of Korean buildings are installed by default while in Germany insect screens are uncommon. This is originated in climatological differences and leads to a reduced air exchange when windows with insect screens are opened. To demonstrate the impact, we compared the effect of insect screens on overheating intensity for both buildings. Therefore, we halved the window ventilation cross-sectional area if insect screens are installed as a simplified assumption based on [52]. The results in Fig. 6 indicate the significance of insect screens on overheating, even for the case that windows are only opened in the morning and evening hours. This underlines that overheating intensity can become problematic if insect screens are added to a window.

\section{Overheating dependency on window ventilation behaviour}

Besides the implementation of insect screens, the passive cooling by air exchange of the flat can be influenced by the inhabitants by varying their window ventilation behaviour internal and external building envelop insulation. Besides the diagrams the derived overheating intensity as TDH (in Kh/a) and maximum room temperature are visualised

in a significant manner [54]. For all simulation variants presented above, the window ventilation profile "Noise" was applied for both buildings (closed windows during night, windows only open from 6 to $10 \mathrm{pm}$ and 6 am to $8 \mathrm{am}$ ). To demonstrate the high potential of passive cooling by natural ventilation, the WVP "Optimum" (visualisation see Table 8, Appendix), taken from Schünemann et al. (2021), is applied. In this WVP the windows of the flats remain open during the whole night (from $6 \mathrm{pm}$ to $8 \mathrm{am}$ ) if outdoor air temperature is lower than room temperature and room temperature is above $24{ }^{\circ} \mathrm{C}$. For the two lowest floors, the "Noise" ventilation profile is applied because of burglary protection, although the windows of the first two floors of the HRB in South Korea are barred. All room doors and internal windows are opened from $6 \mathrm{pm}$ to $8 \mathrm{am}$ to guarantee cross-ventilation and thus show the maximum potential of window ventilation. The differences of overheating intensity in Fig. 7 between the applied WVP "Noise" and "Optimum" are remarkable for both buildings in Berlin and Seoul. For the HRB in Seoul, the maximum temperature decreases by more than $2 \mathrm{~K}$ and the value for TDH of $2100 \mathrm{Kh} / \mathrm{a}$ is more than halved applying the "Optimum" WVP. However, in contrast to the LRB in Berlin, the TDH for the HRB in Seoul remains at a high level, leading to the conclusion that even if optimal window ventilation is applicable the heat burden in the flats remain high in South Korea. Therefore, heat adaptation measures are required to reduce the overheating intensity and is applied to the model in the next section. 

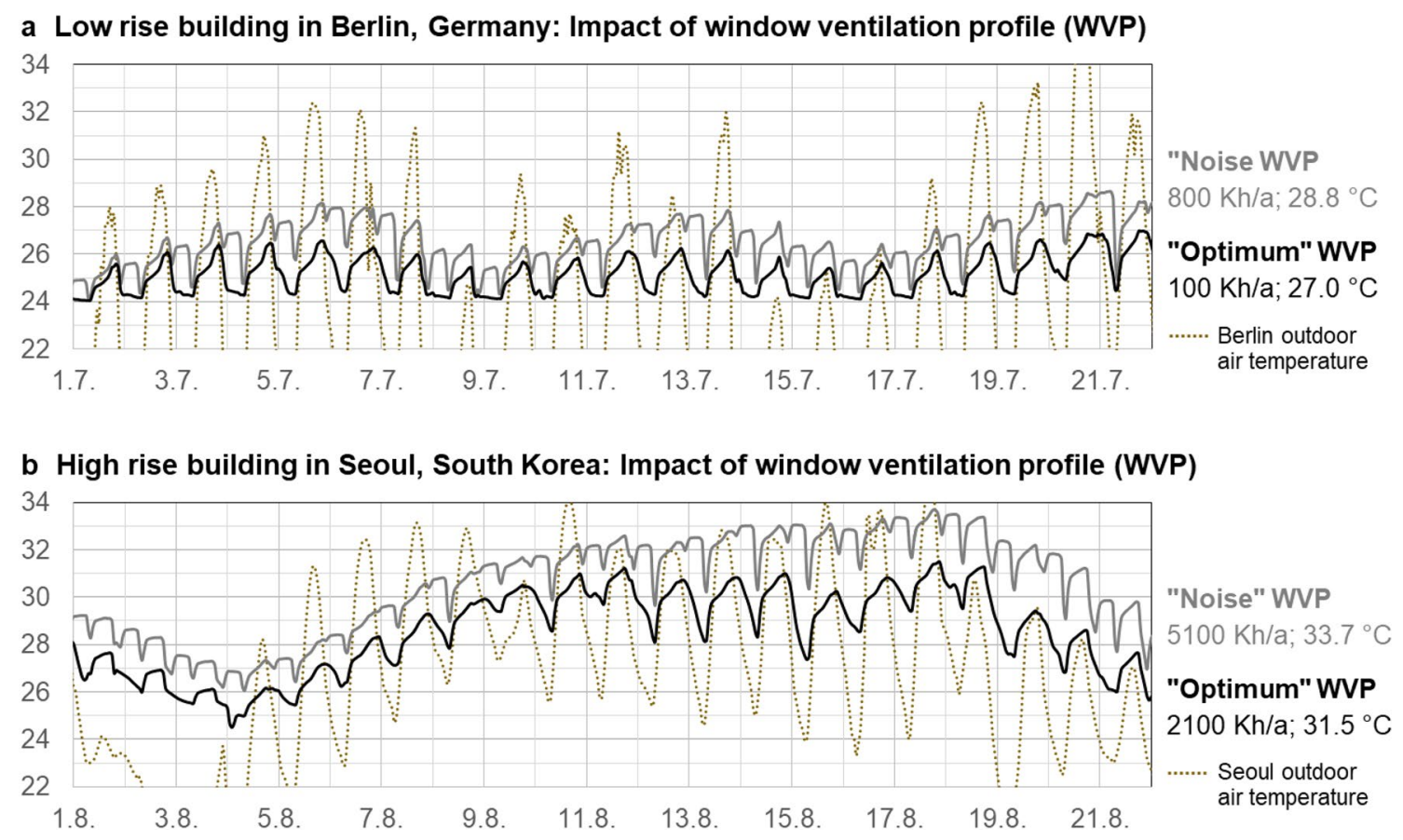

Fig. 7 Impact of different window ventilation profiles (WVP): Evolving room temperatures of the living room (top floor) for the a low-rise building (LRB) in Berlin and b high-rise building (HRB) in Seoul comparing the impact of two WVP "Noise" and "Optimum". Besides

\section{Heat adaptation measures}

For residential buildings, several heat adaptation measures were developed to enhance the heat resilience of a building. Most common measures.

- Reduce the solar heat gain, e.g. by installing shading systems, sun protection glazing or enhancing the insulation of opaque building envelope elements with high solar irradiance [29, 51, 61],

- Increase the air exchange if the room temperatures are higher than the outdoor air, e.g. by installing ventilation systems [62-64],

- Enhance the heat storage capacity of the flat, e.g. by massive construction $[31,36]$.

However, for existing, inhabited buildings care must be taken to find appropriate measures, which are acceptable for the residents. Therefore, subsequent changes to the building structure within the dwelling are mostly ruled out, which makes an increase in heat storage capacity mostly impossible in practice. However, sun shading elements or ventilation systems can often be implemented to existing buildings more easily. For the two chosen HRB and LRB we focus on the influence of the following adaptation measures or combined packages: the diagrams the derived overheating intensity as TDH (in $\mathrm{Kh} / \mathrm{a}$ ) and maximum room temperature are visualised. Windows of the HRB are equipped with an insect screen, whereas for the LRB no insect screens is applied

(1) Installation of an external shading system for all windows (except in the staircase) which are automatically activated when irradiation at the windows surface is above $100 \mathrm{~W} / \mathrm{m}^{2}$. The shading system is defined to transmit $15 \%$ of the solar irradiation in the model.

(2) Combining the external shading system of measure (1) with an installation of a balanced ventilation system in the flats, which is activated if air temperature of the flat is above $23{ }^{\circ} \mathrm{C}$ and the outdoor air is cooler. In this case, unconditioned outdoor air flows into the flat and cools them. The air exchange rate of the ventilation system is defined to be $1 \mathrm{ACH}\left(n=1 \mathrm{~h}^{-1}\right)$, which means an air exchange of $200 \mathrm{~m}^{3} / \mathrm{h}$ for the HRB and $175 \mathrm{~m}^{3} / \mathrm{h}$ for the LRB (a full air exchange of the flat in one hour). Rooms with supply air are living room, bedroom, studying room and kids' room. Rooms with exhaust air are kitchen, bathrooms and for the HRB balconies. In this scenario, the windows remain closed.

(3) Similar to measure (2) but with an air exchange rate of $2 \mathrm{ACH}\left(=1 \mathrm{~h}^{-1}\right)$, meaning a double of air exchange rate.

The impact of the three adaptation measure variants on evolving room temperature time series is illustrated in Fig. 8, and the derived characteristic values of TDH and maximum room temperature are listed in Table 4. For both buildings, 

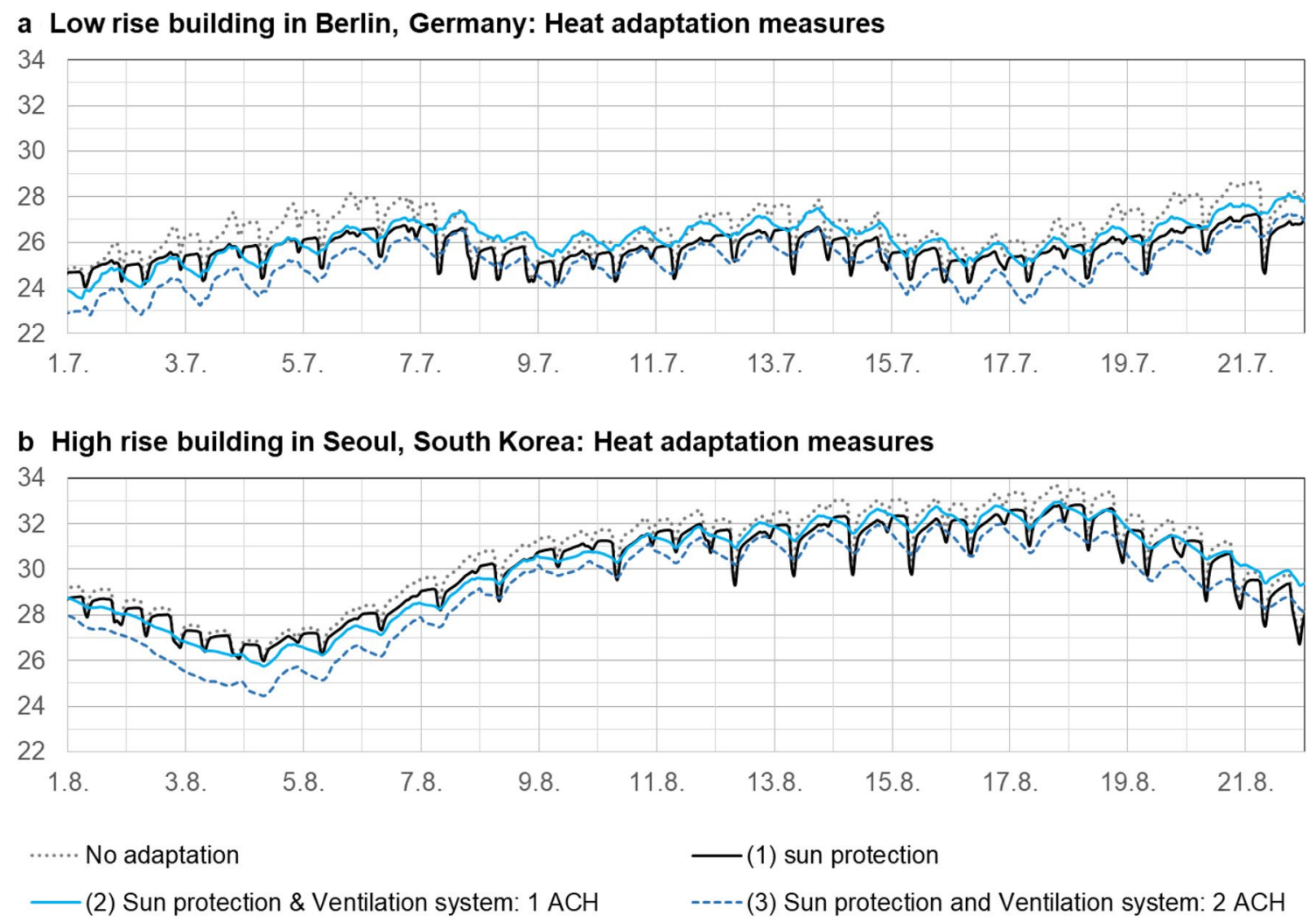

Fig. 8 Heat adaptation measure effectiveness: Evolving room temperatures of the living room (top floor) for the a low-rise building (LRB) in Berlin and b high-rise building (HRB) in Seoul comparing the impact of three different adaptation measures. The derived overheat- ing intensity as TDH (in $\mathrm{Kh} / \mathrm{a}$ ) and maximum room temperature are depicted in Table 5. Windows of the HRB are equipped with an insect screen, whereas for the LRB no insect screens is applied

Table 4 Heat adaptation measure effectiveness: effect of heat adaptation measures on overheating degree by means of TDH and maximum room temperature corresponding to Fig. 8

\begin{tabular}{|c|c|c|c|c|}
\hline \multirow[b]{2}{*}{ Adaptation measure } & \multicolumn{2}{|l|}{ Low-rise building } & \multicolumn{2}{|l|}{ High-rise building } \\
\hline & Overheating (TDH) & $\begin{array}{l}\text { Maximum tem- } \\
\text { perature }\end{array}$ & Overheating (TDH) & $\begin{array}{l}\text { Maximum } \\
\text { tempera- } \\
\text { ture }\end{array}$ \\
\hline No adaptation (reference) & $800 \mathrm{Kh} / \mathrm{a}$ & $28.8^{\circ} \mathrm{C}$ & $5100 \mathrm{Kh} / \mathrm{a}$ & $33.7^{\circ} \mathrm{C}$ \\
\hline Sun protection & $200 \mathrm{Kh} / \mathrm{a}$ & $27.5^{\circ} \mathrm{C}$ & $4200 \mathrm{Kh} / \mathrm{a}$ & $32.8^{\circ} \mathrm{C}$ \\
\hline Sun protection and Ventilation system $1 \mathrm{ACH}$ & $600 \mathrm{Kh} / \mathrm{a}$ & $28.7^{\circ} \mathrm{C}$ & $4000 \mathrm{Kh} / \mathrm{a}$ & $33.0^{\circ} \mathrm{C}$ \\
\hline Sun protection and Ventilation system $2 \mathrm{ACH}$ & $200 \mathrm{Kh} / \mathrm{a}$ & $27.9^{\circ} \mathrm{C}$ & $1600 \mathrm{Kh} / \mathrm{a}$ & $30.5^{\circ} \mathrm{C}$ \\
\hline
\end{tabular}

the installation of sun shading systems (variant (1)) significantly reduces the overheating intensity. For the LRB, this leads to acceptable TDH and maximum room temperature. However, for the HRB the TDH and maximum room temperature remain uncomfortable.

The additional installation of a ventilation system with an air exchange of $1 \mathrm{ACH}$ (variant (2)) only shows a negligible impact for the HRB and a worsening for the LRB. The reason for this is that the windows are closed for the scenario of implementing a ventilation system. This clearly demonstrates that for the LRB the air exchange of opening windows using the WVP "Noise" (for variant (1)) leads to a higher air exchange and thus to a stronger cooling effect than an automated ventilation system with an air exchange rate of $1 \mathrm{ACH}$.

Installing a ventilation system with an air exchange rate of $2 \mathrm{ACH}$ in variant (3) leads to values in TDH for the LRB living room comparable to those of variant (1) with window ventilation. In contrast, the overheating intensity of the HRB in Seoul decreases tremendously. This is highlighted 
Table 5 Comparison of the yearly cooling energy demand for the top floor flat of the low-rise building $\left(65 \mathrm{~m}^{2}\right.$ living area) and the high-rise building ( $80 \mathrm{~m}^{2}$ living area) at both location (Berlin and Seoul) with- out and with adaptation measures (* variant (2): sun protection and ventilation system $1 \mathrm{ACH}$ from Fig. 8)

\begin{tabular}{llll}
\hline & Location & Low-rise building & High-rise building \\
\hline Without adaptation & Both in Berlin, GER & $1794 \mathrm{kWh}$ & $924 \mathrm{kWh}$ \\
& Both in Seoul, KOR & $2112 \mathrm{kWh}$ & $1289 \mathrm{kWh}$ \\
With adaptation* & Both in Berlin, GER & $147 \mathrm{kWh}$ & $291 \mathrm{kWh}$ \\
& Both in Seoul, KOR & $556 \mathrm{kWh}$ & $669 \mathrm{kWh}$ \\
\hline
\end{tabular}

by a lowering in TDH of $3500 \mathrm{Kh} / \mathrm{a}$ and maximum room temperature decrease of around $3 \mathrm{~K}$. Unfortunately, from the practical side ventilation systems with $2 \mathrm{ACH}$, implying $400 \mathrm{~m}^{3} / \mathrm{h}$ air exchange for a HRB flat, are not common in practice because the dimensioning of ventilation systems is typically oriented to fresh air supply. Such high airflows can also induce indoor noise. Another critical issue is that, although the room temperatures could be lowered to a more acceptable level for the HRB in Seoul, the humid climate leads to relative humidity in the flat in the range of 70 to $85 \%$. In combination with the high temperature, this "tropical" indoor conditions show that for the climate of Seoul it is hard to achieve comfortable temperatures by passive heat adaptation measures. One solution might be to use dehumidifier and the other one to install active cooling systems.

\section{Active/technical cooling}

In this section, the living rooms of the flats of both buildings are cooled technically to maximum air temperature of $26^{\circ} \mathrm{C}$ while the neighbouring rooms are unconditioned and only cooled indirectly by open room doors (see floor plans in Fig. 2). For the HRB, the room doors towards the balconies remain closed as well as all windows for both buildings. The comparison of the cooling energy demand (without adaptation measures) in Table 5 exhibits several findings. First, the cooling demand for the LRB is almost twice as high as the demand of the HRB, independent if the buildings are located in Berlin or Seoul. Taken into account that the overheating intensity in the uncooled HRB is higher as in the LRB living room (see Fig. 4) arises the question why the cooling demand seems to differ in a contrary manner. The major difference is found to be originated in the different balcony design. While for the LRB flat only the living room windows are shaded by the balcony and four remaining windows do not have any window shading, the shading situation in the HRB is significantly different (see Fig. 2). Here the closed balconies are heated to by solar gains to air temperatures up to $37^{\circ} \mathrm{C}$. However, these rooms with high solar gains are not actively cooled because the windows to the adjacent rooms remain closed. The cooled adjacent rooms are well shaded by the balconies. Since the balcony windows are assumed to be closed, only the "internal core" of the flat with low solar heat gain needs to be cooled. Additionally, the g-value of the balconies of the HRB is much lower than those of the LRB ( 0.35 to 0.50 , respectively). That the different solar heat gain is responsible for the differences in cooling demand is also demonstrated by the simulation variant including the heat adaption measure (variant (1)) with automated external sun protection systems in Table 6 . While the cooling demand in the LRB is more than halved by the shading, the cooling demand of the HRB is much less affected. Our findings are in agreement with findings from Song et al. (2012) analysing the impact of remodelling of the balcony space to a living space for a high-rise building in Seoul by BPS. The results demonstrate that the indoor temperature increase is around $1 \mathrm{~K}$ and that the cooling demand increases by $22 \%$ in case of remodelling.

Comparing the cooling energy demand for both buildings, it becomes clear that there is no significant difference for the location of Berlin and Seoul. Remembering the much higher overheating intensity of the uncooled buildings in Seoul compared to Berlin in Fig. 4, this seems contradictory at first. The deeper analysis reveals that the strong overheating intensity of the buildings in Seoul is mainly caused by mild nights obstructing effective passive cooling by window ventilation. In contrast, the high cooling energy demand of the buildings for the location of Berlin is caused by the higher direct solar irradiance through the windows compared to the location of Seoul. The cloudy summer in Seoul leads

Table 6 Comparison of the yearly cooling energy demand of the top floor flats in the low-rise and the high-rise building in dependence of different heat adaptation measures. The adaptation measures are taken from Table 5 and Fig. 8

\begin{tabular}{lll}
\hline & $\begin{array}{l}\text { Low-rise build- } \\
\text { ing in Berlin, } \\
\text { GER }\end{array}$ & $\begin{array}{l}\text { High-rise building in } \\
\text { Seoul, KOR }\end{array}$ \\
\hline No measure & $1794 \mathrm{kWh}$ & $1289 \mathrm{kWh}$ \\
$\begin{array}{l}\text { (1) sun protection } \\
\text { (2) Ventilation system }\end{array}$ & $824 \mathrm{kWh}$ & $1056 \mathrm{kWh}$ \\
$\begin{array}{l}\text { (1 ACH) and Sun protec- } \\
\text { tion }\end{array}$ & $147 \mathrm{kWh}$ & $669 \mathrm{kWh}$ \\
\end{tabular}


to a difference in direct solar irradiation sum from June to August of $160 \mathrm{kWh} / \mathrm{m}^{2}$ for Seoul and $292 \mathrm{kWh} / \mathrm{m}^{2}$ for Berlin (see Table 1). An additional factor is the $15^{\circ}$ northern position in latitude of Berlin compared to Seoul leading to a smaller elevation angle of the sun above the horizon in Germany and thus to higher solar irradiance through windows, especially when south-oriented.

Besides these differences induced by building design, different location and different climate, the cooling energy demand for both buildings and locations is significantly lowered when applying passive heat adaptation measures. The results in Table 6 state that applying the variant (2) of adaptation measure (external sun protection in combination with a ventilation system with an air exchange of $1 \mathrm{ACH}$ ) can reduce the cooling energy demand by more than $90 \%$ for the LRB and nearly $50 \%$ for the HRB. Accordingly, passive heat adaptation measure can strongly reduce the cooling energy demand and thus greenhouse gas emissions and thus act parallel as both climate change adaptation and climate change mitigation method. Our findings demonstrate that passive heat adaptation measures should not be neglected when a building is technically (actively) cooled.

\section{Discussion}

\section{Interdependence of building design and climate conditions on overheating intensity and cooling demand}

By analysing the overheating intensity and cooling energy demand of two representative apartment buildings in dependence of heat adaptation measures, building location and present climate conditions, we achieve a deeper understanding of these interrelations. One major outcome is that different building designs are suitable for different countries due to their local climate conditions. In this context, the HRB in Berlin, Germany, would reveal a much higher overheating intensity than the LRB if no active cooling is applied. If both buildings would be located in Seoul, South Korea both buildings show a comparable overheating risk. When active cooling is applied, the HRB cooling energy demand is only half of the LRB, independent of the location. This implies that the LRB is the proper building type for German climate if no active cooling is applied which is the common case in Germany. In contrast, for Seoul, the HRB is more suitable because it reveals a much lower cooling demand when it is actively cooled or similar overheating intensity like the LRB when it is not. This implies that both buildings are designed quite suitable for their locations and the current climate conditions. However, the tremendous decrease in the overheating risk or cooling demand when implementing simple heat adaptation measures (like sun protection or ventilation systems) clearly demonstrates that both buildings are far away from a proper design concerning energy consumption for cooling or heat burden when active cooling is applied or not, respectively.

As a general outcome, we generalised the differences in climate conditions and building design in Germany and South Korea and opposed them in Table 7 including an evaluation whether the individual property is positive or negative concerning the heat resilience of the apartment building. The comparison shows that South Korean climate leads to critical summer conditions making it difficult to achieve comfortable room temperatures only by passive heat adaptation measures. The table also reveals that buildings in both countries have their advantages and disadvantages regarding heat resilience. Whereas the German building stock is mainly designed to be energy-efficient by reducing the heating demand in winter, the South Korean building stock is more focussed on summer conditions but with the trend to enhance the building envelope insulation to achieve a lower heating demand reduction [51]. These disparate developments are originated by the different climate conditions with cooler climate in Germany and long extended hot summer climate in South Korea. In this context, Ihm et al. (2012) demonstrated that double glazing with low solar heat gain coefficient is beneficial for large apartment windows in South Korea. Another important factor regarding heat resilience for not actively cooled flats is that they need to be designed in a way that cross-ventilation is feasible. Our findings show that the kind of natural ventilation has a significant impact on overheating intensity or cooling demand for both Korean and German apartment buildings. These findings are confirmed by Lee et al. (2017) obtaining that natural ventilation for a residential building in Incheon, South Korea, can reduce the cooling energy demand by $60 \%$ in comparison unventilated once. For another German multi-residential building, we demonstrated that the realistic reproduction of window ventilation behaviour is vital to calibrate BPS models to monitored room temperature and its significant impact on overheating [64].

Besides these detailed comparisons of impacts by building design and climate conditions, we analysed the effectiveness of different heat adaptation measures, which result in a tremendous potential on reduction in overheating intensity or cooling demand with simple measures like sun protection systems. This was confirmed by Cho et al. (2014) in a detailed analysis of the impact of building shading devices for a high-rise residential building in Seoul, reducing the cooling energy demand by around $20 \%$ which is in the range of our findings in variant (1) of Table 6 [29]. In addition, our investigation shows that for the LRB type in Germany an even larger reduction in cooling energy demand of more than $50 \%$ can be obtained by external sun protection systems (see Table 6). Comparing the efficacy of heat adaption 
measures, we found that for the design of the LRB external sun protection systems indicate the largest effect while for the design of the HRB the ventilation system (cooling the flat with unconditioned outdoor air) is much more efficient that external sun protection. This is caused by the different glazing types and balcony situations and demonstrates that most suitable heat adaptation measures differ for both building designs and thus for both countries.

According to the authors' knowledge, past overheating studies did not compare overheating of apartment buildings in different countries separating building design and climate condition impact. Our exemplary comparison of South Korea and Germany shows that such comparative approaches can provide new insights concerning heat resilience and suitable climate adaptation measures. Such analysis can lead to a learning effect of different countries from each other to transform their building stock to a higher resilience. Further comparisons of countries with larger differences in climate conditions or buildings designs might lead to new interesting approaches.

\section{Generalisability, caveats and remaining questions}

Although this case study only consist of a comparison of only two different apartment buildings located in two countries, we believe that our findings can be generalised as done in Table 7. We justify this with the fact that detailed analyses of the residential building stock in both countries were performed in advance of this study to find representative buildings for both countries. The chosen HRB and LRB are suitable references of apartment buildings in South Korea and Germany, respectively. However, it should be taken into account that such generalisation can only describe average outcomes. Strong deviations are possible, e.g. by different climate conditions within the country (mountainous region to lowlands) or by different apartment building design. For example, in Germany, a high number of different apartment building types exist [65]. A comparison of a LRB and an older apartment building ("Gründerzeit") was performed earlier [36] with the result that the obtained differences are not such significant as those between the German LRB and the South Korean HRB. Besides the impact of climate conditions, this is caused by larger differences in building design between South Korean and German apartment buildings (e.g. differences in insulation, balcony implementation, window glazing, use of insect screen, building height, etc.) compared to differences within the German building stock. In comparison, in South Korea different apartment types exist as well (like stair, corridor or tower type [66] but commonly reveal the same basic elements, such as internal insulation or glazed balconies which are common for a high number of buildings.
For further investigations, a comparison of detached and semi-detached houses for both countries might also be relevant because around 50\% of the German and $40 \%$ of the Korean flats are originated in this type of residential buildings [41, 43]. The reason that we focussed on apartment buildings is based on the fact that these building types are more generalisable in design while for detached houses a higher diversity in building design and building physics aggravates to draw generalisable conclusions. Some differences in the apartment building design between Germany and Korea are found to be also present for the detached housing type like internal insulation in South Korea and external insulation or monolithic construction in Germany.

Remaining open questions are the implementation of different inhabitant behaviour as well as presence between Germany and South Korea, based on a different cultural and social background. The collaboration of German and South Korean researchers for this study permits a first insight. For example, while in Germany cross -ventilation during night is not such preferred because doors of some rooms are typically closed because of privacy issues, this seems to be more common in South Korea. Here, active cooling devices are mainly installed in the living room and adjacent bedrooms and kids' rooms are cooled indirectly by open room doors during night. Similar observations were made concerning windows remaining open during night, which seems to be more common in South Korean cities. Thus, a representative WVP between apartments in Seoul and Berlin might be different which was only partly addressed by testing the impact of two different WVP (see Fig. 7). In addition, a detailed monitoring of room temperature and humidity for 24 houses in Seoul, done by Bae et al. (2009), shows that inhabitants in Korea tend to activate the cooling devices at high room temperatures which are outside of the indoor thermal comfort zone [47]. This might be an indication that South Korean people have a different perception and adaptive capacity concerning acceptable thermal comfort conditions than Germans which is also not addressed in our study [67]. This aspect could be taken into account in future modelling, for example, with a different limit value for the excess temperature degree hours, in a similar way as it is already applied in the German DIN standard for the different summer climate regions in Germany [58] or by applying an adaptive overheating criteria [68].

A rough assumption in our investigation is that we set the internal heat gain constant at $4.2 \mathrm{~W}$ per $\mathrm{m}^{2}$ living area for both buildings. This can be justified by the fact that the primary objective of this study was to compare the performance of the buildings and that no better data was available. However, differences in operating the buildings by occupants are found to have a significant impact on overheating intensity of rooms and dwellings [54, 62, 64]. 


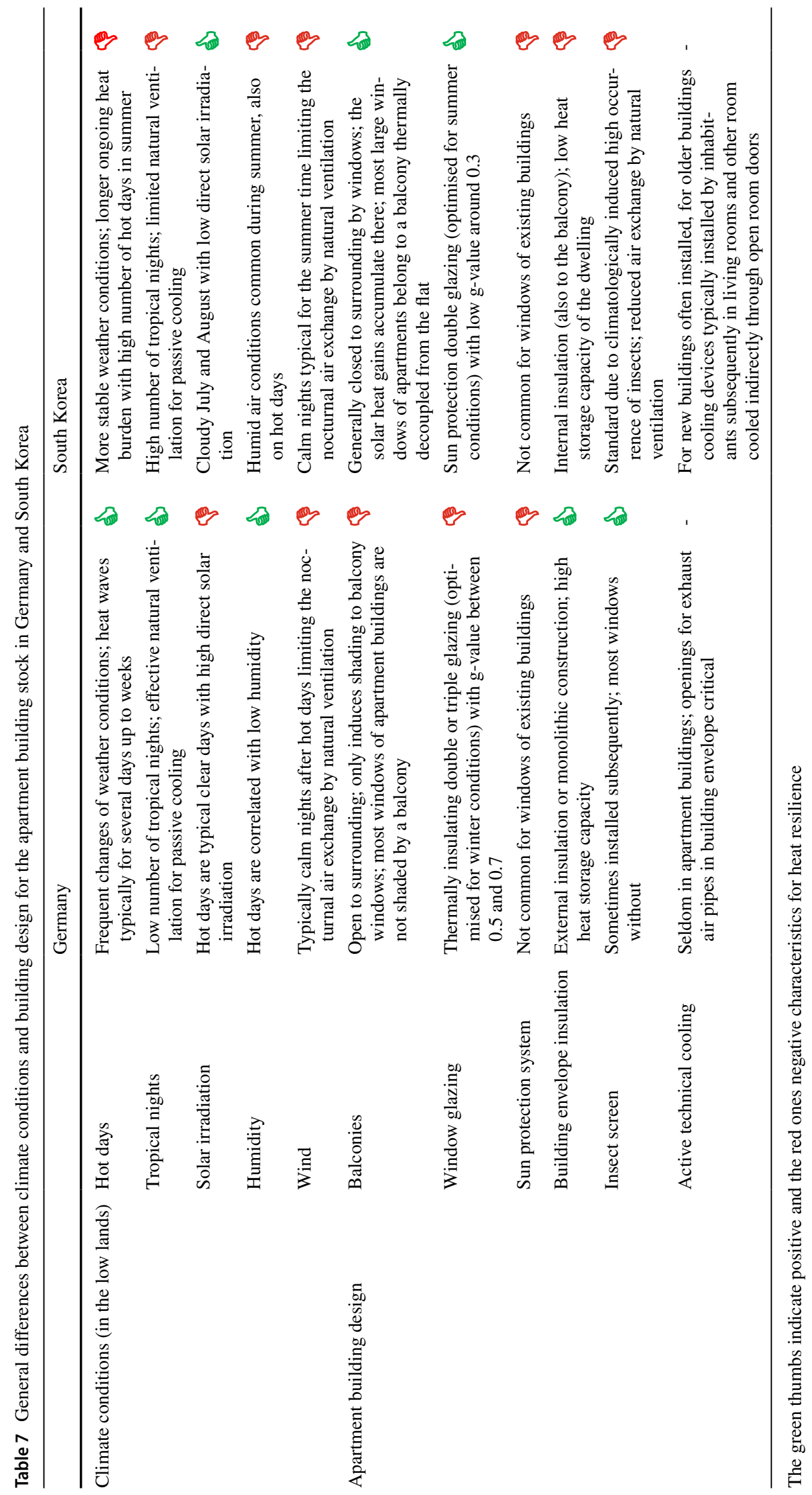


The meteorological conditions are another important boundary condition significantly influencing the overheating intensity. For both countries, the summer varies in air temperature and solar radiation conditions from year to year. We implemented meteorological data representing an average summer for the locations of Seoul and Berlin, comparing the meteorological conditions of the last 30 years. However, for planning issues both buildings should be designed for above average summer stress not only because of common fluctuations from year to year but because of ongoing climate change projected to lead to enhanced heat stress especially in cities [1]. Our findings highlight that an increase in tropical nights is very critical to achieve sufficient passive cooling by natural ventilation. Further simulations using climate projections would be of interest to analyse how overheating intensity or cooling demand of the building might develop in future and whether the buildings are heat resilient under future conditions with, for example, an increase of tropical nights.

\section{Conclusion}

The aim of this study was to analyse the impact of building design and climate condition on the heat resilience of apartment buildings in Germany and in South Korea. One central outcome of the BPS is that the overheating intensity for apartment buildings located in Seoul is significantly larger than in Berlin, caused by the high number of tropical nights in the South Korean climate. If both buildings would be virtually located in the same city, the overheating intensity of the LRB is found to be lower than for the HRB. However, when the flats are cooled technically a higher cooling demand is obtained for the LRB than for the HRB. An explanation for this contradictory appearing observation is given by the different building design, more precisely by the glazed balcony structure and the necessity of insect screens for windows in South Korea. The internal insulation (used as standard in South Korea) of the HRB was found to induce higher overheating intensities because of reduced heat storage capacities. As a geneal outcome Table 7 summarises our findings and opposes which climate conditions and building design issues positively or negatively affect the heat resilience of residential buildings in Germany and South Korea. Implementing several heat adaptation measures to both BPS building models indicate that the overheating risk can be significantly reduced for the LRB if external sun protection is applied (from 800 to $200 \mathrm{Kh} / \mathrm{a}$ ). In combination with a ventilation system used to cool the flat by unconditioned outdoor air, this leads to a significant decrease in overheating intensity for both buildings (from 5100 to $1600 \mathrm{Kh} / \mathrm{a}$ for the HRB in combination with sun protection systems). If the flats are actively cooled, the implementation of heat adaptation measures results in a tremendous decrease in cooling energy demand of up to $92 \%$ for the LRB (from 27.6 to $2.2 \mathrm{kWh} /\left(\mathrm{m}^{2} \mathrm{a}\right)$ ) and $48 \%$ for the HRB (from 16.1 to $\left.8.3 \mathrm{kWh} /\left(\mathrm{m}^{2} \mathrm{a}\right)\right)$. This finding demonstrates that measures can act as both climate adaptation and climate mitigation measures. From the overall comparison we can summarise that glazed balconies (HRB) an external façade insulation (LRB) result in a heat resilient building design. However, if the west- and east-oriented windows are (externally) shaded, the open balcony structure of the LRB is preferred because the building has a better possibility for window ventilation and thus passive cooling than the HRB. From our findings, we advocate that this case study acts as a starting point for further comparative studies on heat resilience for buildings located in different countries and recommend further research to understand how climate mitigation and climate adaptation can be fostered within one measure.

\section{Appendix}

\section{Parametrisation of the apartment buildings in BPS}

For overheating assessment by BPS representing the reality in detail at least hourly resolved profiles of resident's presence and operating electrical devices are required. However, in this article we focus to compare two flats and want to avoid overlaying effect of different room use. Therefore, we decided to define the same internal heat gain (including gains by occupants, equipment and illumination) for all room types applying a constant value of $4.2 \mathrm{~W}$ per $\mathrm{m}^{2}$ living area for $24 \mathrm{~h}$ per day over the whole year. This value is taken from the German standard DIN 4108-2 [58]. For the staircase, balconies, corridors and bathroom no internal heat gain is applied Table(8).

For the BPS, the following boundary conditions and were applied:

- Location of the HRB is Seoul, South Korea; location of the LRB is Berlin, Germany

- Orientation of the building similar to reality (see Fig. 2)

- Shading objects: no shading of surrounding buildings and trees was taken into account, shading of balconies were considered

- Assumed thermal bridge loss coefficient related to all surfaces of the building envelope

- HRB: $0.10 \mathrm{~W} /\left(\mathrm{m}^{2} \mathrm{~K}\right)$ (common for older buildings [69])

- LRB: $0.05 \mathrm{~W} /\left(\mathrm{m}^{2} \mathrm{~K}\right)$ (common for newer or refurbished buildings [69])

- Minimum room air temperature (heating): $22{ }^{\circ} \mathrm{C}$

- Buildings air tightness related to all component surface (weighted by building envelope surface) for both, HRB and LRB: $n_{50}=2 \mathrm{~h}^{-1}$ (due to high air leakage because of 
Table 8 Overview of the applied window ventilation profiles for BPS developed in (Schünemann, 2021 \#146). The last column visualises the hourly resolved daily ventilation time series of the profiles (high bars...fully opened windows, low bars...tilted windows, light blue... cross-ventilation applied)

\begin{tabular}{|c|c|c|c|c|c|c|}
\hline Name & $\begin{array}{c}\text { At } \\
\text { morning } \\
(6-8 \mathrm{am})\end{array}$ & $\begin{array}{c}\text { During } \\
\text { day } \\
(8 \mathrm{am}-6 \\
\mathrm{pm})\end{array}$ & $\begin{array}{c}\text { Even- } \\
\text { ing } \\
(6-10 \\
\mathrm{pm})\end{array}$ & $\begin{array}{c}\text { Night- } \\
\text { time } \\
(10 \mathrm{pm}- \\
6 \mathrm{am})\end{array}$ & $\begin{array}{c}\text { Cross } \\
\text { ventilation }\end{array}$ & Cooling efficiency \\
\hline Optimum & $\begin{array}{c}\text { fully } \\
\text { opened }\end{array}$ & closed & closed & $\begin{array}{c}\text { fully } \\
\text { opened }\end{array}$ & yes \\
\hline Noise & $\begin{array}{c}\text { fully } \\
\text { opened }\end{array}$ & closed & $\begin{array}{c}\text { fully } \\
\text { opened }\end{array}$ & closed & yes & \\
\hline
\end{tabular}

outside air diffusers in windows according [68], Table B.1)

The simulation software IDA ICE ensures that wind- and temperature gradient-driven air exchange through windows and between adjacent rooms is considered. This is done taken into account wind flows through a building by considering pressure coefficient (calculated by a simplified algorithm in IDA ICE) of the individual façade and roof elements. The location of the investigated buildings was assumed to be semi-exposed by the AIVC standard. This approach enables the possibility to display wind-driven air exchanges in the building as well as the effect of crossventilation by open room doors. In addition, temperature gradient-driven air exchange through room doors and windows is included as well. That both are done in a realistic manner was proven by a comparing monitored and simulated room temperatures of another apartment building using IDA ICE [64].

The wind- and temperature gradient-driven infiltration is calculated in IDA ICE by assuming an $n_{50}$ (air exchange rate coefficient at $50 \mathrm{~Pa}$ pressure difference) value of $2 \mathrm{~h}^{-1}$ (according to DIN EN 15,242, Table B.1 for average leakages [68]) for both buildings.

Acknowledgements The authors thank Yukyung Park, David Schiela (both IÖR Dresden) and Stefanie Kunze (HTW Dresden) for the detailed research and provision of the apartment building information.

Author contribution The manuscript was written by CS and revised by SS and RO. The simulation model of the Korean apartment building was created by SS (including detailed research and provision of the apartment building information) and of the German building by CS. The simulations were performed and analysed by CS.

Funding Open Access funding enabled and organized by Projekt DEAL. The study was carried out with basic funding from the Leibniz Institute of Ecological and Regional Development (IOER) within the scope of the project "Assessment of resilience and adaptation to climate change of residential buildings focussing heavy rain and summer heat" (ResAdBuildings).

Data availability Excel calculations that support the findings of this study presented in the charts are available from the corresponding author upon reasonable request.

\section{Declarations}

Conflict interest The authors have no competing interests to declare.

Open Access This article is licensed under a Creative Commons Attribution 4.0 International License, which permits use, sharing, adaptation, distribution and reproduction in any medium or format, as long as you give appropriate credit to the original author(s) and the source, provide a link to the Creative Commons licence, and indicate if changes were made. The images or other third party material in this article are included in the article's Creative Commons licence, unless indicated otherwise in a credit line to the material. If material is not included in the article's Creative Commons licence and your intended use is not permitted by statutory regulation or exceeds the permitted use, you will need to obtain permission directly from the copyright holder. To view a copy of this licence, visit http://creativecommons.org/licenses/by/4.0/.

\section{References}

1. IPCC.: IPCC-Report AR5 climate change 2014: impacts, adaptation, and vulnerability_-part B regional aspects (Intergovernmental Panel on Climate Change). IPCC (2014)

2. Manoli, G., et al.: Magnitude of urban heat islands largely explained by climate and population. Nature 573(7772), 55-60 (2019)

3. Mohajerani, A., Bakaric, J., Jeffrey-Bailey, T.: The urban heat island effect, its causes, and mitigation, with reference to the thermal properties of asphalt concrete. J Environ Manage 197, 522-538 (2017)

4. Head, K., et al.: Report of the Systematic Review on the Effect of Indoor Heat on Health (WHO Housing and Health GuidelinesWeb Annex D). WHO-World Health Organization, Geneva (2018)

5. Toulemon, L., Barbieri, M.: The mortality impact of the August 2003 heat wave in France: investigating the "harvesting" effect and other long-term consequences. Popul. Stud. (Camb) 62(1), 39-53 (2008) 
6. Adekunle, T.O., Nikolopoulou, M.: Thermal comfort, summertime temperatures and overheating in prefabricated timber housing. Build. Environ. 103, 21-35 (2016)

7. Baborska-Narożny, M., Stevenson, F., Grudzińska, M.: Overheating in retrofitted flats: occupant practices, learning and interventions. Build. Res. Inf. 45(1-2), 40-59 (2016)

8. Fosas, D., et al.: Mitigation versus adaptation: does insulating dwellings increase overheating risk? Build. Environ. 143, 740759 (2018)

9. Grey, C.N., et al.: The short-term health and psychosocial impacts of domestic energy efficiency investments in low-income areas: a controlled before and after study. BMC Public Health 17(1), 140 (2017)

10. Jenkins, D.P., et al.: Probabilistic climate projections with dynamic building simulation: predicting overheating in dwellings. Energ Build. 43(7), 1723-1731 (2011)

11. Lomas, K.J., Porritt, S.M.: Overheating in buildings: lessons from research. Build. Res. Inf. 45(1-2), 1-18 (2016)

12. Mavrogianni, A., et al.: Inhabitant actions and summer overheating risk in London dwellings. Build. Res. Inf. 45(1-2), 119-142 (2016)

13. Mavrogianni, A., et al.: Urban social housing resilience to excess summer heat. Build. Res. \& Inf. 43(3), 316-333 (2015)

14. Mavrogianni, A., et al.: Building characteristics as determinants of propensity to high indoor summer temperatures in London dwellings. Build. Environ. 55, 117-130 (2012)

15. Mourkos, K., et al.: Assessing the application and limitations of a standardised overheating risk-assessment methodology in a realworld context. Build. Environ. 181, 107070 (2020)

16. Mourkos, K., et al.: (2020) The impact of accurately modelling corridor thermodynamics in the overheating risk assessment of multi-residential dwellings. Energy Build. 224, 110302 (2020)

17. Mulville, M., Stravoravdis, S.: The impact of regulations on overheating risk in dwellings. Build. Res. \& Inf. 44(5-6), 520-534 (2016)

18. Patidar, S., et al.: Statistical techniques to emulate dynamic building simulations for overheating analyses in future probabilistic climates. J. Build. Perform. Simul. 4(3), 271-284 (2011)

19. Petrou, G., et al.: The summer indoor temperatures of the English housing stock: exploring the influence of dwelling and household characteristics. Build. Serv. Eng. Res. Technol. 40(4), 492-511 (2019)

20. Porritt, S.M., et al.: Ranking of interventions to reduce dwelling overheating during heat waves. Energy Build. 55, 16-27 (2012)

21. Symonds, P., et al.: Overheating in English dwellings: comparing modelled and monitored large-scale datasets. Build. Resea. \& Inf. 45(1-2), 195-208 (2016)

22. Taylor, J., et al.: The relative importance of input weather data for indoor overheating risk assessment in dwellings. Build. Environ. 76, 81-91 (2014)

23. Tink, V., et al.: Measuring and mitigating overheating risk in solid wall dwellings retrofitted with internal wall insulation. Build. Environ. 141, 247-261 (2018)

24. Vellei, M. et al.: Investigating the overheating risk in refurbished social housing. In: Proceedings of 9th Windsor Conference: Making Comfort Relevant (2016)

25. Guo, H., et al.: Evaluation of the summer overheating phenomenon in reinforced concrete and cross laminated timber residential buildings in the cold and severe cold regions of China. Energies 13(23), 6305 (2020)

26. Ali, S.I.A., Szalay, Z.: Overview and analysis of the overheating effect in modern sudanese buildings. Pollack Periodica 15(3), 208-219 (2020)

27. Laouadi, A., Bartko, M., Lacasse, M.A.: A new methodology of evaluation of overheating in buildings. Energy Build. 226, 110360 (2020)
28. Gamero-Salinas, J.C., Monge-Barrio, A., Sánchez-Ostiz, A.: Overheating risk assessment of different dwellings during the hottest season of a warm tropical climate. Build. Environ. 171, 106664 (2020)

29. Cho, J., Yoo, C., Kim, Y.: Viability of exterior shading devices for high-rise residential buildings: case study for cooling energy saving and economic feasibility analysis. Energy Build. 82, 771-785 (2014)

30. Lee, S.-W., et al.: Cooling energy reduction effect of parallel double-window system operation in residential buildings in South Korea. Indoor Built Environ. 28(5), 636-658 (2017)

31. Eikemeier, S., Wimmer, R., Mahdavi, A.: Prevention of overheating risk: assessment of a building project with lightweight construction in Austria. In: Proceedings of the enviBUILD 2019, p. 57-62 (2020)

32. Hodzic, N., et al.: Overheating mitigation in buildings: a computational exploration of the potential of phase change materials. In: MATEC Web of Conferences, vol. 282 (2019)

33. Congedo, P.M., Baglivo, C., Centonze, G.: Walls comparative evaluation for the thermal performance improvement of low-rise residential buildings in warm mediterranean climate. J. Build. Eng. 28, 101059 (2020)

34. Ayikoe Tettey, U.Y., Gustavsson, L.: Energy savings and overheating risk of deep energy renovation of a multi-storey residential building in a cold climate under climate change. Energy $\mathbf{2 0 2}$, 117578 (2020)

35. Ascione, F., et al:: Summer overheating in a new multi-storey building in Berlin: numerical study for improving the indoor microclimate. Energy Proced 75, 1305-1314 (2015)

36. Schünemann, C., et al.: Mitigation and adaptation in multifamily housing: overheating and climate justice. Build Cities 1(1), 36-55 (2020)

37. BBR.:Testreferenzjahre von Deutschland für mittlere, extreme und zukünftige Witte-rungsverhältnisse. Bundesamtes für Bauwesen und Raumordnung (BBR) (2014)

38. ASHRAE.: ASHRAE IWEC2 Weather File for SEOUL (KOR_ SEOUL_471080_IW2). American society of heating, refrigerating and air-conditioning engineers (2011)

39. DWD.:Climate Data Center DWD. [cited 2020 10-05]; Available from: https://www.dwd.de/DE/klimaumwelt/cdc/cdc_node.html (2011)

40. KMA.:Climate Information for Seoul, Korea. Available from: https://www.kma.go.kr/eng/weather/climate/worldclimate.jsp (2020)

41. Destatis, Bautätigkeit und Wohnungen - Bestand an Wohnungen. 2018, Statistisches Bundesamt (Destatis): Germany.

42. Destatis.: Bevölkerung nach Geschlecht und Staatsangehörigkeit. Available from: https://www.destatis.de/DE/Themen/Gesellscha $\mathrm{ft}$-Umwelt/Bevoelkerung/Bevoelkerungsstand/Tabellen/zensusgeschlecht-staatsangehoerigkeit-2019.html (2019)

43. KOSIS.: Statistics Korea 2018: Population Census 2018. 2018. Available from: http://kosis.kr/statHtml/statHtml.do?orgId=101\& tblId=DT_1JC1521\&conn_path=I3.

44. KOSIS.: Population Index of South Korea for the year 2019. 2021. Available from: https://kosis.kr/visual/nsportalStats/index.do? menuId $=$ all

45. Statistica.: Wohnfläche je Einwohner in Wohnungen in Deutschland von 1991 bis 2019 . Available from: https://de.stati sta.com/statistik/daten/studie/36495/umfrage/wohnflaeche-jeeinwohner-in-deutschland-von-1989-bis-2004/ (2019)

46. Statistik. Regionalstatistik Berlin-Brandenburg. Available from: https://www.statistik-berlin-brandenburg.de/regionalstatist iken/r-gesamt_neu.asp?Ptyp $=410 \&$ Sageb $=31000 \& \mathrm{creg}=\mathrm{BBB} \&$ anzwer $=9$ (2019) 
47. Bae, C., Chun, C.: Research on seasonal indoor thermal environment and residents' control behavior of cooling and heating systems in Korea. Build. Environ. 44(11), 2300-2307 (2009)

48. MOLIT.: Detailed guidelines for preventing condensation in apartment houses. 2014; Available from: http://www.molit.go. $\mathrm{kr} / \mathrm{USR} /$ policyData/m_34681/dtl.jsp?id=3708 (2014)

49. Kim, J. Y., Kim, Y. I., Kim, S. H.: Study of apartment terrace condensation characteristics with respect to locations (2019)

50. Song, D., Choi, Y.-J.: Effect of building regulation on energy consumption in residential buildings in Korea. Renew. Sustain. Energy Rev. 16(1), 1074-1081 (2012)

51. Ihm, P., et al.: Impact of window selection on the energy performance of residential buildings in South Korea. Energy Policy 44, 1-9 (2012)

52. Kittas, C., et al.: The impact of insect screens and ventilation openings on the greenhouse microclimate. Trans. ASABE 51(6), 2151-2165 (2008)

53. EQUA, IDA indoor climate and energy 4.8 SP1. 2018, EQUA Simulation AB: Stockholm, Sweden (2018)

54. Schünemann, C., Schiela, D., Ortlepp, R.: How window ventilation behaviour affects the heat resilience in multi-residential buildings. Build. Environ. 202, 107987 (2021)

55. CIBSE.: Technical memorandum 52: the limits of thermal comfort: avoiding overheating in European buildings (CIBSE TM52: 2013). 2013, London: the chartered institution of building services Engineers London (2013)

56. CIBSE.: Guide A: Environmental design (CIBSE Guide A: 2015). 2015, London: the chartered institution of building services engineers London (2015)

57. CIBSE.: Design methodology for the assessment of overheating risk in homes (CIBSE TM59: 2017), The chartered institution of building services engineers London, London (2017)

58. DIN4108-2.: DIN 4108-2 Wärmeschutz und Energie-Einsparung in Gebäuden Teil 2: Mindestanforderungen an den Wärmeschutz (German Institute for Standardization). 2013, Beuth Verlag GmbH: 10772 Berlin (2013)

59. EN_15251.: DIN EN 15251-2007: Indoor environmental input parameters for design and assessment of energy performance of buildings addressing indoor air quality, thermal environment, lighting and acoustics (2007)
60. Vandentorren, S., et al.: August 2003 heat wave in France: risk factors for death of elderly people living at home. Eur J Publ. Health 16(6), 583-591 (2006)

61. Kuhn, T.E., Bühler, C., Platzer, W.J.: Evaluation of overheating protection with sun-shading systems. Sol. Energy 69, 59-74 (2001)

62. Ji, Y., Lee, A., Fernando, T.: Dynamic thermal simulation of advanced natural ventilation in buildings: current and future usage, UK exemplar. Archit. Eng. Des. Manage. 16(4), 1-17 (2019)

63. Mavrogianni, A., et al.: The impact of occupancy patterns, occupant-controlled ventilation and shading on indoor overheating risk in domestic environments. Build. Environ. 78, 183-198 (2014)

64. Schünemann, C., Schiela, D., Ortlepp, R.: Guidelines to calibrate a multi-residential building simulation model addressing overheating evaluation and residents' influence. Buildings 11(6), 242 (2021)

65. Schinke, R., et al.: Damage estimation of subterranean building constructions due to groundwater inundation-the GIS-based model approach GRUWAD. Nat. Hazard. 12(9), 2865-2877 (2012)

66. Lee, S., Park, S.: Morphological transformation of building blocks of apartment complexes in busan. J. Archit. Inst. Korea Plan. \& Des. 35(8), 3-14 (2019)

67. Nguyen, A.T., Singh, M.K., Reiter, S.: An adaptive thermal comfort model for hot humid South-East Asia. Build. Environ. 56, 291-300 (2012)

68. EN_15242, DIN 15242 (2007).: Ventilation for buildings-calculation methods for the determination of air flow rates in buildings including infiltration (2007)

69. BMI.: Gesetz zur Einsparung von Energie und zur Nutzung erneuerbarer Energienzur Wärme- und Kälteerzeugung in Gebäuden (Gebäudeenergiegesetz-GEG). In: Bundesgesetzblatt Jahrgang 2020 2020, Bundesministerium des Innern, für Bau und Heimat: Bonn, Germany (2020)

Publisher's Note Springer Nature remains neutral with regard to jurisdictional claims in published maps and institutional affiliations. 